Document downloaded from:

http://hdl.handle.net/10251/93326

This paper must be cited as:

Aragones, L.; Serra Peris, JC.; Villacampa, Y.; Saval, JM.; Tinoco, H. (2016). New methodology for describing the equilibrium beach profile applied ti teh Valencia's beachs. Geomorphology. 259:1-11. doi:10.1016/j.geomorph.2015.06.049

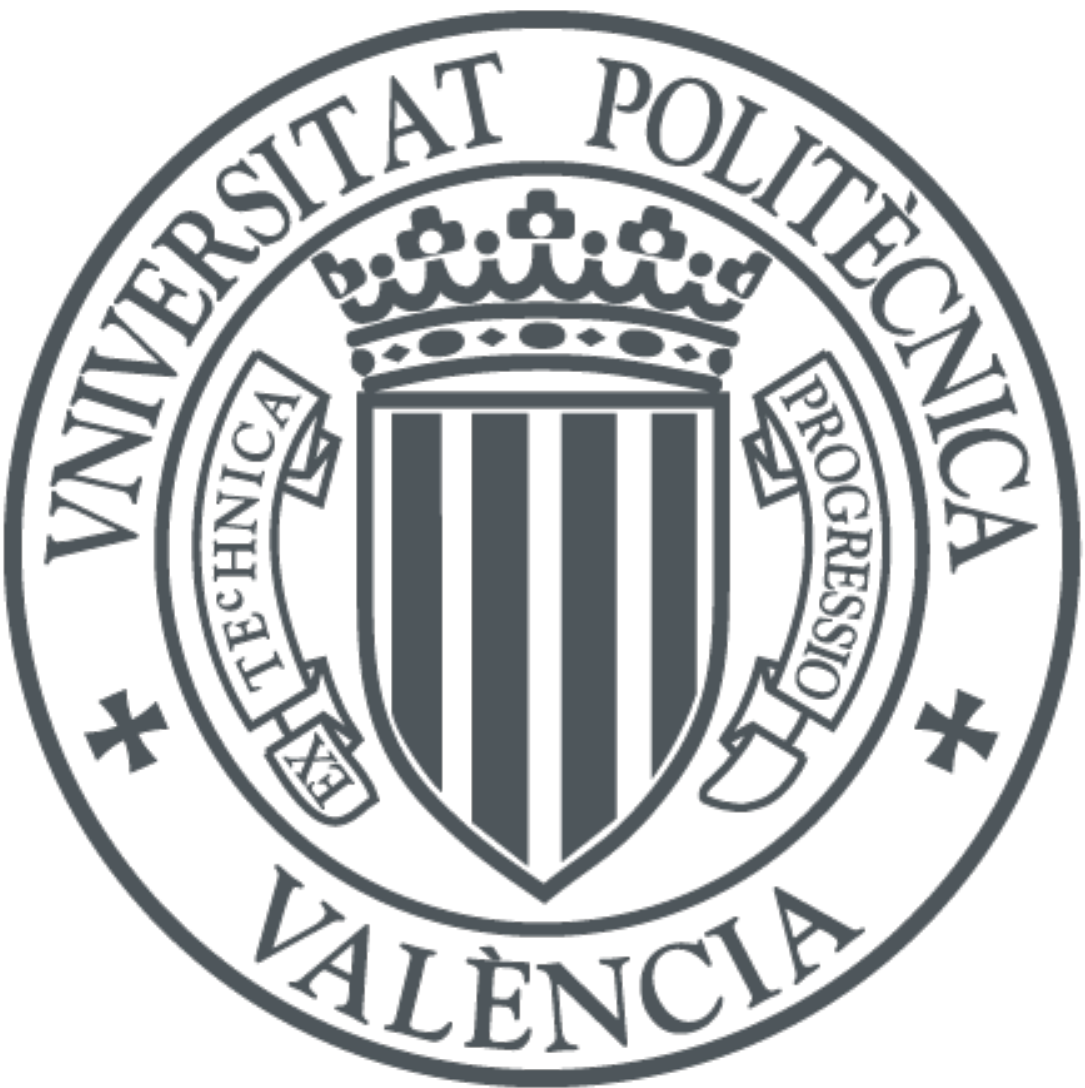

The final publication is available at

http://doi.org/10.1016/j.geomorph.2015.06.049

Copyright Elsevier

Additional Information 


\section{Accepted Manuscript}

New methodology for describing the equilibrium beach profile applied to the Valencia's beaches

L. Aragonés, J.C. Serra, Y. Villacampa, J.M. Saval, H. Tinoco

PII: $\quad$ S0169-555X(15)30059-3

DOI: $\quad$ doi: $10.1016 /$ j.geomorph.2015.06.049

Reference: $\quad$ GEOMOR 5294

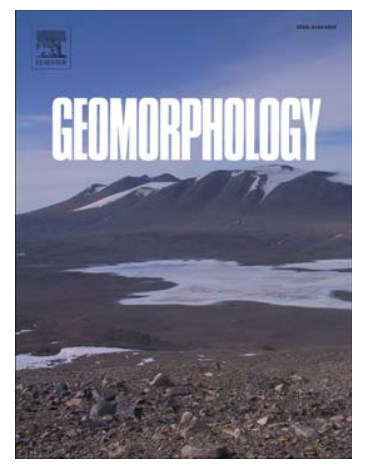

To appear in: $\quad$ Geomorphology

Received date: 19 June 2014

Revised date: $\quad 9$ June 2015

Accepted date: 28 June 2015

Please cite this article as: Aragonés, L., Serra, J.C., Villacampa, Y., Saval, J.M., Tinoco, H., New methodology for describing the equilibrium beach profile applied to the Valencia's beaches, Geomorphology (2015), doi: 10.1016/j.geomorph.2015.06.049

This is a PDF file of an unedited manuscript that has been accepted for publication. As a service to our customers we are providing this early version of the manuscript. The manuscript will undergo copyediting, typesetting, and review of the resulting proof before it is published in its final form. Please note that during the production process errors may be discovered which could affect the content, and all legal disclaimers that apply to the journal pertain. 


\title{
New methodology for describing the
}

\section{equilibrium beach profile applied to}

\section{the Valencia's beaches.}

\author{
L. Aragonés(a), J.C. Serra(b), Y. Villacampa (c), J.M. Saval(d), H. Tinoco(e).
}

(a) Assistant Professor, Dept. of Civil Engineering, University of Alicante, San Vicent del Raspeig s/n, 03690 Alicante, Spain. e-mail: laragones@ua.es

(b) Lecturer, Dept. of Transportation, ETSI Caminos, Polytechnic University of Valencia, Camino de Vera s/n, 46022 Valencia, Spain (corresponding author). E-mail: jserra@tra.upv.es

(c) Lecturer, Dept. Applied Mathematics. University of Alicante, San Vicent del Raspeig s/n, 03690 Alicante, Spain. E-mail: villacampa@ua.es

(d) Lecturer, Dept. of Construction, University of Alicante, San Vicent del Raspeig s/n, 03690 Alicante, Spain. E-mail: jm.saval@ua.es

(e) MSc Civil Engineer, Dept. of Civil Engineering, University of Alicante, San Vicent del Raspeig s/n, 03690 Alicante, Spain. e-mail: hugotinocolopez@gmail.com

\section{Abstract}

Mathematical models used for the understanding of coastal seabed morphology play a key role in beach nourishment projects. These projects have become the fundamental strategy for coastal maintenance during the last few years. Accordingly, the accuracy of these models is vital to optimize the costs of coastal regeneration projects. Planning of such interventions requires methodologies that do not generate uncertainties in their interpretation. A study and comparison of mathematical simulation models of the coastline is carried out in this paper, as well as elements that are part of the model that are a source of uncertainty. The Equilibrium Profile (EP) and the offshore limit corresponding 
to the Depth of Closure (DoC) have been analysed taking into account different timescale ranges. The results have thus been compared using data sets from three different periods which are identified as present, past and future. Accuracy in data collection for the beach profiles and the definition of the median grain size calculation using collected samples are the two main factors that have been taken into account in this paper. These data can generate high uncertainties and can produce a lack of accuracy in nourishment projects. Together they can generate excessive costs due to possible excess or shortage of sand used for the nourishment.

The main goal of this paper is the development of a new methodology to increase the accuracy of the existing equilibrium beach profile models, providing an improvement to the inputs used in such models and in the fitting of the formulae used to obtain seabed shape. This new methodology has been applied and tested on Valencia's beaches.

Key words: Depth of Closure, beaches profiles, $D_{50}$, nourishment, volumetric error

\section{Introduction}

Knowledge of the morphology of beach profiles is needed to solve many coastal engineering problems. It is therefore important to characterise the equilibrium beach profile (EP). Indeed, the EP is essential for its application in several coastal engineering fields, for instance, a) beach nourishment design Hallermeier, 1981; Davison et al., 1992; Stive et al., 1992; Hinton and Nicholls, 1998), b) shoreface nourishment design (Grunnet et al., 2004), c) coastal defence structure design (Shinohara and Tsubaki, 1966; Noble, 1978; Jiménez and Sánchez-Arcilla, 1993), d) active zone delimitation for the calculation of nourishment volumes and estimation of coastal sediment balance ( Hands and Allison, 1991; Houston, 1995; Capiobianco et al., 2002), and e) numerical models of coastal morphodynamics (Kraus and Harikai, 1983; Larson and Kraus, 1992; Inman et al., 1993). An example of its use is in the calculation of volumes needed for the implementation of coastal nourishment. Dean and Dalrymple (2004) propose three avenues of research for possible development of a theory to determine the equilibrium beach profile. These are:

- Kinematic approximation: an attempt is made to predict the movements of the sand particles by describing the forces acting on them (Eagleson et al., 1963).

- Dynamic approximation: a macroscopic balance of constructive and destructive forces is considered.

- Empirical approximation: a purely descriptive approximation representing the attempt to adjust beach profiles to the most common forms found in nature, using parameters determined by means of adjustment or dimensional adjustment techniques.

This study is based on the empirical approach. In this respect, the first experimental studies of beach profiles were performed by Waters (1939) and Saville (1957) showing a concave shape where a steeper slope is observed in the wet beach area. Concurrently, Rector (1954), under controlled laboratory conditions (uniform sets of waves), established an invariant profile, from which Bruun (1954) and later Dean (1977) presented the potential function (1), the most commonly used in coastal engineering: 


$$
h(x)=A \cdot x^{B} \rightarrow h(x)=A \cdot x^{2 / 3}
$$

where $h$ corresponds to the theoretical profile depth according to distance to shoreline $x$ and $A$ is a parameter known as scale factor and $B$ is a parameter to be adjusted according to local characteristics and conditions which govern sediment transportation (Pilkey et al., 1993). Dean (1977) assumed that the equilibrium in beach profiles was directly related to a constant dissipation of wave energy per water volume unit, obtaining a value of $2 / 3$ for the parameter $B$. Since then, research efforts have been focused on finding appropriate parameter values in order to obtain more suitable representations for profile. Thus, Moore (1982) and Dean (1987) established the relationship (2) between said parameter and the rate of particle sedimentation:

$$
A=0.067 \cdot w^{0.44}
$$

where $w$ is the particle settling velocity (in $\mathrm{cm} / \mathrm{sec}$ ). The value of $\mathrm{w}$ can be obtained using expression (3) from Hallermeier (1981a) when average grain sizes are between 0.15 and $0.85 \mathrm{~mm}$ and water temperature is between $15^{\circ}$ and $20^{\circ}$ :

$$
w=14 \cdot D_{50} 1.1
$$

This potential formula (1) has been validated by authors such as Stockberger and Wood (1990) in the Great Lakes of America, and Kaiser and Frihy (2009) in the Nile Delta, in which a comparison of their best adjustment against exponential formulations is made. According to field observations highlighted by Pilkey et al. (1993), different combinations of parameters $A$ and $B$ in the potential formula (1) produce a reasonable likeness to natural profiles. They also assert that it is bad practice not to assume that there is a net loss of sand after the depth of closure (DoC).

Hallermeier (1981b) and Nicholls et al. (1998) identify two zones with different levels of morphodynamic activity: a dynamically active region (Coastal Zone) with significant vertical movement of profile, and an inactive region nearer the sea (Shoal Zone) in which vertical movement is lower and whose outer limit $\left(d_{i}\right)$ is the offshore point. The separation depth of both areas is $d_{1}$ - a depth defined by Hallermeier $(1978 ; 1981 b)$ as the DoC. Therefore Dean (2003) considers the depth of closure $d_{1}$ as the limit of the equilibrium profile and the most suitable depth for the design of beach nourishments.

Regarding parameter $B$ in the potential formula (1), Boon and Green (1988) suggest that a value of 0.55 instead of $2 / 3$ provides a better adjustment for the Caribbean beaches they analysed. This is because the beaches analysed by said authors are more reflective and were formed by sediments with a higher content of carbonate, reaffirming once again that parameter $A$ must be influenced by the characteristics of the incidental waves and the properties of the sediment profile to be studied when setting parameter $B$.

Not establishing any clear relationship, Kriebel et al. (1991) introduced an adjustment in their beaches of parameter $A$ (4) when $w$ is between 1 and $10 \mathrm{~cm} / \mathrm{s}$ :

$$
A=2.25 \cdot\left(\frac{w^{2}}{g}\right)^{1 / 3}
$$


One of the first to use an exponential adjustment formulation equilibrium profile was Bodge (1992) who derived the expression (5):

$$
h=B \cdot\left(1-e^{-k x}\right)
$$

where $k$ determines the profile concavity and $B$ defines the offshore water depth which the profile reaches asymptotically. Subsequently, Sierra et al. (1994a, b) provide comparisons with field data from the Catalan coast and deduce that the expressions which best fit the Catalan seabed are the exponential (6) and rational type (7), the potential type expression (1) providing worst adjustments.

$$
\begin{aligned}
& e^{h}=A\left(x+x_{0}\right)^{B} \\
& h=\frac{x}{A+B x}
\end{aligned}
$$

Regarding the use of exponential expressions for the equilibrium profile adjustments, Dai et al. (2007) proposed the expression (8) by adding a variable parameter $C$ based on their studies of the southern coast of China. This study only provides values of the variables for the beaches tested, showing a general formulation for the remaining cases:

$$
h=A \cdot e^{B x}+C
$$

However, authors like Komar and McDougal (1994) used an exponential expression (9) by introducing a different parameter $S_{0}$ corresponding to the slope of the beach, and whose formulation has a unique coefficient to be adjusted $k$, which determines the degree of profile concavity:

$$
h=\frac{s_{0}}{k} \cdot\left(1-e^{-k x}\right)
$$

On the other hand, studies conducted by Romanczyk et al. (2005) indicate that the logarithmic function is that which best fits their beach profiles. Turker and Kabdasli (2006) introduced expression (10) for the $A$ parameter of the potential formulation (1) that takes into account both the effect of the dissipation of wave energy and the influence of water density:

$$
A=\frac{a_{1}}{\left(\kappa^{2} \cdot X_{L}\right)^{2 / 3}} \cdot\left[\frac{3}{5} H_{b}{ }^{2} \cdot h_{b}{ }^{-1 / 2}+\Gamma^{2} \cdot h_{b}^{3 / 2}\right]^{2 / 3}
$$

where $\Gamma$ is the wave decay constant and $X_{L}$ corresponds to the average displacement of particles that are deposited when dynamic stability is achieved.

Another representative aspect in this kind of study is the number of profiles used for the adjustment. Dean (1977) used 504 profiles, ranging from a depth of 0 to $-15 \mathrm{~m}$, collecting data every $15 \mathrm{~m}$ for a distance of $365 \mathrm{~m}$ from the shoreline, in a specific time frame. These 504 profiles were obtained from the East Coast of the USA and the Gulf of Mexico and were classified into 10 groups represented by an average profile. These average profiles were used by Bodge (1992) to verify the exponential expression (7).

Dean (1977) and Bodge (1992) have used an adjustment by means of the minimum squared method to obtain their formulations. However, the 504 profiles vary greatly in both accuracy and density (Dolan et al., 1977). In this respect, Boon and Green (1988) take 
their measurements from up to $120 \mathrm{~m}$ from the shoreline. Kaiser and Frihy (2009), using 1990 data in their study of the Nile Delta, took sections twice a year up to a -10 maximum depth in good weather conditions, once in spring and once in autumn. In their studies a total of 37 sections were compared, taking their length to a closure depth estimated by field data collection, which is between 2 and $4 \mathrm{~m}$. However, the authors assert that this depth can reach up to $12 \mathrm{~m}$ during extreme storm periods.

Karunarathna et al. (2009) obtain their data from 8 profiles, from which 38 bathymetric surveys are available for each one, covering the period 1987 to 2005. Komar and McDougal (1994) used a single profile from Nile Delta claiming that it was representative of many profiles measured by Egyptian researchers from the Coastal Research Institute of Alexandria. These profiles were taken to represent Hallermeier's depth of closure (1978, 1981b). Romanczyk et al. (2005) used sections from various periods and places: between 1966 and 1990 on the Gold Coast of Australia, between 1980 and 2000 from the east coast of America, and measurements taken over a period of ten months from 1999 to 2000 on the island of Jerba (Mediterranean). Furthermore, Sierra et al. (1994a) used 82 sections from the Catalan coast covering $105.2 \mathrm{~km}$ between 1989 and 1990.

This study aims to improve knowledge of the equilibrium profile obtained from the Valencian coast, with the following objectives:

1. establish the period of time needed to develop an accurate equilibrium beach profile formula;

2. study the influence the accuracy of field profiles has as a variable in obtaining an equilibrium profile formulation;

3. obtain the equilibrium beach profile function which best fits the Valencian coast; and

4. establish what type of function (potential, exponential, rational) is better suited to equilibrium profiles and produces the lowest volumetric errors.

In general, the research is based on the premise of creating models with user friendly functions which are easy to interpret.

\section{Regional setting}

Valencia is situated in the south-east of Spain, located in a built-up area of the Mediterranean coast. Its shorelines are dominated by floodplains and sandy coastal lowlands. Its beaches are home to delta fans, alluvial cones, dunes, lagoons, capes and harbours on the coast and bars by the seaside. The entire littoral system has evolved through means of a combination of terrestrial sedimentary contributions, subsequently shaped by marine waves.

The Valencian coast is embedded within a microtidal system of astronomical amplitude ranging between 20 and $30 \mathrm{~cm}$, with the meteorological surge sometimes reaching $0.76 \mathrm{~m}$. (Ecolevante. 2006). The wave incident characterization of the area studied was based on data provided by the directional buoy from net "REDCOS" 1619 at coordinates $0.20^{\circ} \mathrm{W}$ 
longitude $39.51^{\mathrm{O}} \mathrm{N}$ latitude, with a depth of $50 \mathrm{~m}$. The study period extends from 08-062005 to $01-11-2013$.

Data have been analyzed using CAROL statistical software developed by the University of Cantabria, obtaining characteristic wave height and period associated with intermediate water for the study area. Subsequently these data have been translated to deep water using the methodology proposed by Marine Works Recommendation (ROM 0.3-91 1991). From the results it is clear that dominant storms are from the ENE, with a significant wave height of $3.9 \mathrm{~m}$ and period of $11.6 \mathrm{~s}$, the most common being those from the E with $2.8 \mathrm{~m}$ significant wave height and $10.6 \mathrm{~s}$ period. The average flux in the area has a direction of 81.35 ${ }^{\circ}$ from the north, which means the shoreline tends to be perpendicular to this direction. This last assertion confirms Valencian beaches have a tendency for longitudinal transportation in the north-south direction. This longitudinal transport can be neglected by translation of the profiles to the same point of origin (matching the waterfront) according to Türker and Kabdaşli (2006).

Some of the beaches classified in the area of study have been the subject of maintenance and coastal defence processes. Breakwaters have been implemented due to the state of recession in which the Valencian shoreline is found. The present study has focused on the sandy beaches of Valencia that have not been subjected to this type of intervention. This means that from the 45 beaches in the province totalling a length of $96,690 \mathrm{~m}, 28$ beaches have been studied, $62,519 \mathrm{~m}$ in total, which gives a representation of $64.65 \%$. Fig. 1 shows the location of the accurate beach profiles named P1 to P5-N-S, recorded using the Bar Profiler in two time periods 1992-1997 and 2008-2012, and the location of Ecolevante beach profiles, recorded using echo sounders during the year 2006.

\section{FIGURE 1}

Figure 1. Location map of the study area. Location of Bar Profiler and Ecolevante beach profiles.

Regarding the characteristics of sediments in the study area, 463 samples have been analyzed from the dry beach (Ecolevante, 2006) concluding that their median sizes, $\mathrm{D}_{50}$, are between $0.452 \mathrm{~mm}$ and $0.172 \mathrm{~mm}$ (Table 4). The procedure for sampling was performed using a Van Veen grab sampler. The content of the dredger was deposited in a bucket, and subsequently labeled and transferred into bags. The labeled bags were placed in portable coolers with ice and sent to the laboratory, where granulometric tests (Ecolevante, 2006) were performed. $\mathrm{D}_{50}$ was calculated based on granulometric tests carried out by the Dirección General de Costas (DGC) and the formulas of Folk and Ward (1957), which process the data statistically using a computer program, characterizing the samples according to Wentworth (1922) .

$\mathrm{D}_{50}$ is the most important statistical parameter for characterization of the sediment. This represents the median particle size and can be obtained from the cumulative distribution curve. It is the size for which half the sample by weight is coarser and half is finer (Dean and Dalrymple, 2004). 


\section{Materials and Methods.}

The methodologies or procedures used to obtain beach profiles are diverse. These methods range from the use of nautical charts (Hayden et al., 1975), the use of topographic levels and depth manometers operated by divers (Boon and Green, 1988; Kaiser and Frihy, 2009), or the use of sounding lines for measuring the depth with ultrasound (Hayden et al., 1975; Kaiser and Frihy, 2009; Karunarathna et al., 2009) and the use of other methods which provide precision profiles (Nicholls et al., 1998).

In this study two methods have been used, a method called Bar Profiler (BP) described by Serra and Medina (1996) and the other using echo sounders. The first method consists of a precise bathymetric section survey and relies on transferring the classical topography from land to sea. The Bar Profiler method (BP) provides a connected bar system with an articulate foot and a crown with two reflecting prisms for determining elevation of beach profile, independently of average sea level due to astronomical tide and wave oscillation. This removes uncertainties from level determination which produce measurement errors, leading to a determination of beach profile with a maximum margin of error of one centimeter. The other system used is based on echo sounders. Multibeam echo-sounder includes complementary tools such as a differential GPS, a motion sensor VRU-2 and SGBROWN gyroscope. Three ships and three different sounders were used in the calculation of profiles by this method; two multibeam sounders installed in ships "Divi Divi" and "Toton" respectively, and one single beam sounder. In addition auxiliary sounding techniques were used, consisting of correcting the speed of sound through water for analysis and data processing and also obtaining a digital form of the results. The expected margin of error in such probes can reach $30 \mathrm{~cm}$ (Ecolevante, 2006).

Another way to obtain a validated formulation for calculating the equilibrium profile is based on canal trials. Both Vellinga (1984) and Turker and Kabdasli (2006) obtain their data from laboratory tests. However, obtaining the representative parameters in the field for their introduction in beach profile formulae is the main problem which the engineer suffers when trying to use formulae which come from laboratory tests. For example, obtaining the A parameter using Turker and Kabdasli's (2006) formula (10) is extremely difficult due to the complexity of the dependent variables.

Detailing the collation of field parameters for the use of a particular formulation is not only linked to laboratory testing but it must also be considered in the formulations that are derived from profiles taken in the field. As a result, a verification of the adequacy of processes used has been sought in this paper. Therefore, 159 precision sections obtained by the Bar Profiler method (BP) covering an area of 17,679.6 m (18.28\% of the Valencian coast) in two time periods 1992-1997 and 2008-2012 have been used. The frequency of profile collection has not been constant. Between 1992-1994 measurements were taken every two months and every 4 months, and between 1994-1997 and 2005-2012 in April and October of each year. However, sample collection in the observed periods has always been used to obtain information on profiles in summer and winter. On the other hand, 128 profiles obtained from the bathymetry of 2006 developed by Ecolevante (2006) and obtained by using echo sounders have been used. 
The study and comparison of data obtained from these two methods is expected to confirm the adequacy of the combined use of results from these two methods of data collection in the field. In the research it has been clarified that the use of data from only one period is enough to validate a model due to the formulae obtained by the time period of 2006 fitting the data collection from the two time periods 1992-1997 and 2008-2012. The procedure followed for the adjustment and development of a validated formulation is based on a model established over the years 1992-1997 (analyzing the past) and 20082012 (analyzing the future).

Bathymetric profiles are available from 28 beaches studied in 2006 (64.65\% of the Valencian coast), however, precision profiles are available for only 5 of these beaches (18.28\% of the coastline). Due to there being two different ways of measuring beach profiles, in accurate precision profiles the measured level 0 has been transferred in order to unify the start of the profiles. The methodology for adjusting the equilibrium profile formula in Valencian beaches is based on obtaining the best adjustment and least volumetric errors. The accuracy of adjustment was based on calculating the difference between the actual surface profile obtained in the field and the one estimated from the obtained function, the result of which has been multiplied by the length of beach sample in order to obtain the volumetric error. The procedure followed to obtain the best adjustment function is based on the calculation of a model represented by a similar potential function to (1), performing two processes at once: on the one hand, an adjustment that minimises the error in surface per profile, and on the other hand, the visualisation of this adjustment to minimise volumetric error. All this is based on the Ecolevante (2006) profiles obtained, which were further validated subsequently by the precision profiles of the time periods 1992-1997 and 2008-2012. To this end, different mathematical models were generated in accordance with potential, exponential, rational, and logarithmic functions. For model generation from experimental data, SPSS computer software has been used. Statistics libraries found within Excel software have also been utilized as a tool for the treatment of experimental data.

The main variant introduced in this methodology compared to that carried out by authors such as Dean (1987) is validated by achieving a better adjustment in the area or volume error. Therefore, a detailed description of the steps followed in the preparation of this new methodology is given.

1. The first step carried out was setting a reference point through the translation of each profile from its own datum (level 0) to the datum of the first profile taken. The aim of this process is avoiding the influence of longshore and cross-shore sediment transport on the profile. This datum point was the level 0 of the first profile. This was done to avoid the influence of longitudinal and transverse sediment transport on the profile. Then theoretical profiles obtained from the potential formula (1) (Dean, 1977) have been simulated by calculating: the scale parameter $A$ obtained by Dean (1987) in beaches studied using formulas (1), (2) and (3). For this, it is essential to know the median sediment size $\mathrm{D}_{50}$. This size has been obtained by the taking of samples on the dry beach by means of two methods: a) determining the arithmetic average of all samples collected from the dry beach $\left(\mathrm{D}_{50, \text { aritmetic }}\right)$; and $\left.\mathrm{b}\right)$ combining all sieve samples to obtain a sample from 
each beach $\left(\mathrm{D}_{50 \text {,weight }}\right)$. In addition, the regression coefficient $\mathrm{R}^{2}$, surface errors per profile unit, the relative mean square error MSE/Var, mean error $\varepsilon$, the relative percentage error on the mean depth $\delta$ and prediction diagram have been calculated.

Relative mean square error MSE/Var is obtained by formula (11), the mean error by formula (12) and the percentage error using equation (13), where $h_{m i}$ corresponds to measured depth values, $\mathrm{h}_{\mathrm{CI}}$ to calculated depth values, $\mathrm{n}$ is the number of values and $\mathrm{p}$ is the number of free parameters in the expression:

$$
\begin{gathered}
\frac{M S E}{\operatorname{Var}}=\frac{\frac{\sum_{i=1}^{n}\left(\mathrm{~h}_{\mathrm{mi}}-\mathrm{h}_{\mathrm{ci}}\right)^{2}}{n}}{\operatorname{Var}\left(\sum_{1}^{n}\left(h_{m i}\right)\right.} \\
\varepsilon=\sqrt{\frac{\sum_{i=1}^{n}\left(h_{m i}-h_{c i}\right)^{2}}{n-p}}(12) \\
\delta=\frac{\varepsilon}{\sqrt{\frac{1}{n} \sum_{i=1}^{n}\left(h_{m i}\right)^{2}}}
\end{gathered}
$$

2. Potential type models (1) were generated from experimental data for each beach, calculating the parameters $A$ and $B$ for equation (1). Statistics libraries from Excel software have been used to this end. In addition, as the seaward limit of the active region is the closure depth, and hence the outer limit of the equilibrium profile of Dean (2003), it was considered necessary to study the equilibrium profile to the limit of two zones of sediment movement: closure depth $d_{1}$ (Birkemeier, 1985; Hallermeier, 1978) and offshore point or onshore outer limit ( $\left.\mathrm{d}_{\mathrm{i}}\right)$ (Hallermeir 1983). The procedure followed by the authors to obtain $d_{l}$ is based on $H_{s, 12}$ wave height (exceeded for only 12 hours per year) for each period of profiles studied and $d_{i}$ (Hallermeier, 1983) with $H_{r m s}$ height (root-mean-square wave height) for the same time periods studied.

3. Parameter $B$ has been set to a value of $2 / 3$ as Dean (1977) did because it is the most prevalent value according to the study carried out at point 2 (above). Once value $B$ has been set, parameter $A$ is obtained for the equation (1) model, both for precision profiles and Ecolevante profiles. To obtain the best value for parameter $A$, the minimization of surface errors was used as model selection criteria. In addition, information parameters for models are estimated, such as: Pearson regression coefficient $\mathrm{R}^{2}$, average error $\varepsilon$, percentage error on the mean depth $\delta$ and graphic representation of real data versus estimated values (prediction diagram). If the model is good, all the data will be around the 1:1 regression line.

4. Subsequently, with a new parameter $A$, which is obtained in point 3 (above) by adjusting the potential formula (1) for each beach. The profiles for each beach have been mathematically calculated and compared to theoretical results obtained from formulas (1) and (2) using the average size $\left(D_{50}\right)$ collected from the dry beach as input. The results were compared using the errors described in point 3 .

5. After analyzing the potential function, other functions have been determined, such as the logarithmic function (which has been rejected due to its poor results), exponential (5) as that of Bodge (1992), and rational (7) as that of Sierra et al. (1994b). Both precision profiles and Ecolevante profiles have been used for this 
analysis. Moreover prediction diagram was performed for each function, as well as all model representations and finally compared to actual data.

6. Subsequently, a comparison of the errors defined by equations (11), (12) and (13) produced by each of the models developed is made, as well as errors in surface area per profile unit. In 5 beaches precision profiles and Ecolevante profiles have been used. In the 23 remaining beaches it has only been possible to analyze the model errors generated by using the Ecolevante bathymetric data due to the absence of precision data.

\section{Results}

\subsection{Profile limits}

This section clarifies the necessary limits to be considered when measuring profiles in the field to adjust the formulation for the equilibrium profile on the Valencian coast. With this in mind, data are available for a period of 20 years, within which there are beaches which show important longshore and cross-shore sediment transport, as shown in Fig. 2. However, as is confirmed by Turker and Kabdasli (2006) this transport can be disregarded for the sandy beaches which have been studied. This is why the precision profiles have been moved from shoreline level 0 of each profile to the same point.

\section{FIGURE 2}

Figure 2. North and South beach of the Valencia harbour evolution in plant view.

The depth obtained for $d_{l}$ is between 5.79 and $6.67 \mathrm{~m}$ according to Hallermeier (1978), and 4.41 and $5.2 \mathrm{~m}$ according to Birkemeier (1985), being found at a mean distance of $469.3 \mathrm{~m}$ from the coast. Regarding the depth $\mathrm{d}_{\mathrm{i}}$ (Hallermeier, 1983) for the studied period is from 5.13 to $7.86 \mathrm{~m}$, reaching an average distance of $640.2 \mathrm{~m}$ from the coast. Both distances have been considered as limits for the beach and shore in our study.

Fig. 3 shows the statistical distribution of closure depth obtained for each beach depending on the method used for its calculation. The curve with circles corresponds to closure depth estimated by Birkemeier (1985), and fits better in the study area than Hallermeier's (1981b) represented by the curve with triangles. The real DoC has been obtained using the SDDC method (Hinton and Nicholls, 1998).

FIGURE 3

Figure 3. Profile limit, Birkemeier's depth.

\section{2. $D_{50}$ Median Size}

By analysing the formulations proposed by authors such as Vellinga (1984), Boon and Green (1988), Dean (1991), Kriebel et al. (1991), Pilkey et al. (1993) and Turker and Kabdasli (2006), a clear tendency to relate the equilibrium profile to the median sediment size $\mathrm{D}_{50}$ is observed. However, none of these provide a clear methodology for obtaining this parameter in the field, leading to uncertainty in exactly how to obtain a representative 
sample of the beach of study to obtain the $\mathrm{D}_{50}$ from their formulations. It should be noted that this parameter has a high sensitivity in all the formulations studied, since small variations in the $\mathrm{D}_{50}$ cause significant variations in the profile obtained.

To represent the median particle size for a beach, several samples are taken along the whole beach. These samples are tested in the laboratory individually and jointly, the particle size of the samples is obtained following UNE-EN 933-1:2012. Using individual

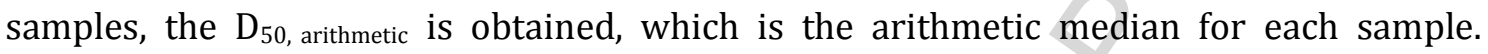
However, this method provides erroneous $D_{50}$ when the sediment sample is not representative of the beach. Therefore, we use a second method to unite all samples and obtain an average median size, $\mathrm{D}_{50 \text {, weight }}$.

In Table 1 and Fig. 4 we can see the variation in the calculation of Dean's equilibrium

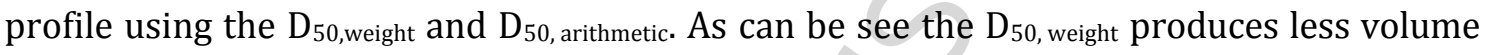
errors than $\mathrm{D}_{50 \text {,arithmetic }}$ and the profile agrees better with real data. This allows us to affirm that the $\mathrm{D}_{50 \text {, weight }}$ is the best for representing the median size of the beach.

TABLE 1

Table 1. Volume error between real data and Dean function (1 y 3) using $D_{50, \text { weight }}$ and $D_{50, \text { Arithmetic. }}$

FIGURE 4

Figure 4. Variation Dean's profile calculated with the $\mathrm{D}_{50, \text { weight }}$ or $\mathrm{D}_{50, \text { arithmetic.. }}$

\subsection{Formula used for adjusting the equilibrium profile}

Following the methodology described in section 3 , the following results have been obtained.

Table 2 shows results for the Dean (1987) model using formulas (1), (2) and (3). Parameter B from formula (1) has been estimated as $2 / 3$ and the values for $A, D_{50 \text {,arithmetic }}$

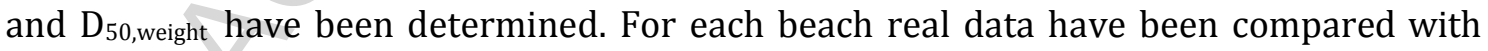
that obtained with the Dean (1987) model, using the following statistical error measurement indices: surface error per profile unit $\left(\mathrm{Em}^{2}\right)$ Pearson regression coefficient $\left(\mathrm{R}^{2}\right)$, relative mean square error MSE/Var, mean error $\varepsilon$, error percentage relative to mean depth $\delta$ and prediction diagram. Fig. 5 shows the prediction diagrams developed for 3 of the studied beaches.

TABLE 2

Table 2. Data used and errors made by Dean function using the $D_{50}$, weight and $D_{50}$, arithmetic versus real Ecolevante profiles.

FIGURE 5

Figure 5. Prediction diagram of Dean function and real Ecolevante profiles.

Following the methodology defined by Dean (1977) least square fitting of potential formula (1) has been performed for each beach by calculating $\mathrm{R}^{2}$ and $A, B$ parameters. The results obtained show that the mean value of parameter $B$ is precisely $0.662 \approx 0.67$ at $d_{i}$ 
depth, which coincides with the parameter set by Dean (1977). The results are shown in Table 3.

\section{TABLE 3}

Table 3. Least square fitting of the potential function with Ecolevante data.

Due to the value obtained for parameter $B$ being approximately the same as that obtained by Dean (1977), $2 / 3$ has been considered the ideal value for parameter $B$. New models have been generated of equation (1) type, in which $B=2 / 3$ and value $A$ corresponds to the best adjustment to the experimental data obtained from Ecolevante profiles (2006) for the two depths studied, $\mathrm{d}_{\mathrm{i}}$ and $\mathrm{d}_{\mathrm{l}}$. Moreover, statistical error measurement indices are obtained and shown in Table 4: surface error per profile unit $\left(\mathrm{E}\left(\mathrm{m}^{2}\right)\right)$, Pearson regression coefficient $\left(R^{2}\right)$, relative mean squared error (MSE/Var), mean error $(\varepsilon)$ and percentage relative error $(\delta)$. The prediction diagram is also obtained (Fig. 6).

\section{TABLE 4}

Table 4. Errors made when fitting Ecolevante profiles with the potential function and setting the value of $B$ to $2 / 3$.

\section{FIGURE 6}

Figure 6. Prediction diagram of potential function versus real data for Alboraya, Saler and Corinto beaches.

In Table 5, modelled $A$ parameter values are compared, from experimental precision data and Ecolevante (2006). Surface errors between the values obtained for each $A$ and the real profiles have also been compared. Table 5 does not include the surface errors for Pinedo beach as there are not as many precision profiles available as for the other 4 beaches.

The \% symbol in Table 5 refers to the error made when using a one year time-series (2006 in the case studied) instead of collecting several time-series from different years (19951996 / 2008-2012 in the studied case).

\section{TABLE 5}

Table 5. Errors made using one year profiles (Ecolevante 2006) instead of precision profiles. The \% symbol refers to the percentage of error.

In Table 6, models generated with Ecolevante (2006) data for the rational type (7) and exponential function (6) have been analyzed. For each model the following statistical error measurement indices are obtained: surface error per profile unit $\left(\mathrm{Em}^{2}\right)$, Pearson regression coefficient $\left(R^{2}\right)$, relative mean square error (MSE/Var), mean error $(\varepsilon)$, percentage relative error $(\delta)$.

\section{TABLE 6}

Table 6. Errors made when setting Ecolevante profiles with the exponential and logarithmic function.

To compare the models a prediction diagram (Fig. 7) and the accuracy of adjustment (Fig. 8 ) were used. It can be seen how the potential and the rational functions agree better with real data (Fig. 8). 


\section{FIGURE 7}

Figure 7. Prediction diagram between real data and each function (Dean function, potential, exponential and rational).

FIGURE 8

Figure 8. Comparison of each of the functions used (potential, rational, exponential and Dean function) with real data.

To calculate the volume error, first the surface error is obtained and then this is multiplied by the length of the beach. The relative volume errors were obtained for each of the beaches and then all together, dividing each volume error by the maximum volumetric error obtained. Table 7 shows all the errors (relative volume error, relative mean squared error (MSE/Var), mean error $(\varepsilon)$ and percentage relative error $(\delta)$ for each function used.

TABLE 7

Table 7. Relative volume error, relative mean squared error (MSE/Var), mean error ( $\varepsilon$ ) and percentage relative error $(\delta)$ for each function used (Dean weight, Arithmetic Dean, Rational, Exponential and Potential function).

\section{Discussion}

The tendency of the beach profile morphology is naturally concave (Saville, 1957; Waters, 1939). The start and end of the profile are two elements that require specific focus because the coastline is constantly changing, and can be subject to significant changes which may have occurred over a period of time, such as changes due to longshore transport, erosion or coast accretion owing to beach nourishment or simply by marine agents (waves, currents, etc.). Beach changes can be corrected by translating level 0 of all profiles horizontally to the same point. This point is level 0 of the first profile. For microtidal tidal beaches such as the area studied $(20-30 \mathrm{~cm})$, the errors made by not moving the vertical profile are minimal. However, for macrotidal beaches, the tidal range when the profile is taken must be considered. On the other hand, there are beaches which, due to their location (near capes) or protective measures implemented on them, are subject to diffraction or energy reduction phenomena. This type of beach has been omitted from this study due to its shape in plan and profile being different from the open beaches (Iglesias et al., 2009a, b). Therefore, we assert that the beach and shore profile can be represented by models defined from potential, exponential, logarithmic and rational functions. The results obtained with each of the functions are compared with real profiles, evaluating the errors committed both graphically and mathematically.

First, as has been observed in the results of Table 1 and Fig. 4, the $\mathrm{D}_{50 \text {,weight }}$ obtained for the entire suite of beach samples is the most suitable method for obtaining representative beach median particle size. This is because $D_{50 \text {,weight }}$ allows correction for distortions caused by non-representative samples from the beach.

Previous research studies are of the utmost importance in the development and adjustment of new methodologies. In Table 2 it can be observed that the Pearson regression coefficient $\mathrm{R}^{2}$ is not a good parameter to consider in this type of adjustment. For example, the surface error per profile unit for La Dehesa is $3121.8 \mathrm{~m}^{2}$ with a regression coefficient of $\mathrm{R}^{2}=0.991$, whilst Pinedo beach has a surface error of $6.4 \mathrm{~m}^{2}$ but a regression coefficient of $\mathrm{R}^{2}=0.962$. This means that the difference in the Pearson 
adjustment is not as important as the difference in the surface error. Furthermore Table 7 shows relative mean squared errors MSE/Var of 5.63\% and $4.18 \%$, and a mean error $\varepsilon$ of 0.689 and 0.642 for La Dehesa and Pinedo beaches, respectively. Therefore, the relative mean squared errors and the mean error are the best representing the adjustment of the mathematical model.

It has been observed that the average values obtained for parameter $B$ (Table 3 ) are 0.662 for $d_{i}$ and 0.646 for $d_{1}$, values approximating the adjustment determined by Dean (1977), and whose standard deviation is 0.0458 and 0.0450 , respectively. Therefore, once exponent $B$ has been adjusted with potential formula 2/3 (Table 3), Ecolevante (2006) profiles for all studied beaches are adjusted (Table 2). Two morphodynamic limits, coastal zone $d_{1}$, as shoal zone $d_{i}$, are the limits of profile adjustment, adjustment (Hallermeier, 1978, 1981; Birkemeier, 1985; Rijkswaterstaat, 1987). It has been analyzed, using the same methodology for testing the Dean (1977) function, that for both depths, results are very similar (Table 4). Here it can been seen that the worst surface error $\left(E\left(\mathrm{~m}^{2}\right)\right)$, comparing actual data with the adjustment, is $6.943 \mathrm{~m}^{2}$ in $\mathrm{d}_{\mathrm{i}}$ and $-1.715 \mathrm{~m}^{2}$ in $\mathrm{d}_{\mathrm{l}}$, which is in contrast to results obtained from the Dean (1987) function in the area studied, where the lowest surface error is $6.4 \mathrm{~m}^{2}$ (Table 2). The maximum and minimum potential function of the statistical parameters for the depth di and $\mathrm{dl}$ are respectively: MSE/Var error of 6.23-0.10 and $\epsilon$ error of 0.764-0.105 in $d_{i}$ and MSE/Var error of 5.46-0.35 and $\epsilon$ error of 0.469-0.001 in $\mathrm{d}_{1}$.

Models obtained at one time can be very good, but can their period of validity be useful for beach nourishment? Ghazali and Hisham (2007) believe that regeneration should be performed every 5 years. This is the reason why the comparison between this adjustment and precision profiles of up to 20-year periods can give information about the validity of our hypothesis. Furthermore it has been found that in the $17,680 \mathrm{~m}$ of beach studied with precision profiles, that in adjustments using less accurate field data (Ecolevante, 2006) the dispersion results improved in respect to the variation between the approximate function and the actual data, which ranges from a maximum of $1538 \mathrm{~m}$ to $1178 \mathrm{~m}$ and from a minimum of $-1396 \mathrm{~m}$ to $-0818 \mathrm{~m}$. Therefore in Table 5 adjustments were compared for Ecolevante profiles (2006) and precision profiles for $d_{l}$ and $d_{i}$ depths. Similar results are observed in parameter $A$ for all depths studied. It can also be seen that error is minimal compared with data for the same beaches in table 2 (adjustment formulas (1), (2) and (3)) or Table 6 (adjustment made for other models such as exponential and rational). This can be observed in examples made by prediction diagram, as listed in Fig. 7. This leads us to the following assertions:

a. errors produced by adjusting the equilibrium profile, with data collection for a one-year period, are less than using the models tested in other areas, and

b. the potential function is best suited to the shape of the profiles in the study area.

If generated models are analyzed only within a single period of time it can be seen that the potential model is the one which gives the best results (Table 7). On the one hand, it is the function in which least volume errors are produced. The parameters which produce the best results are: relative mean squared error (MSE/Var), mean error $(\varepsilon)$ and percentage relative error $(\delta)$. This fact can be seen in table 7. The Saler beach example (Fig. 8) provides a clearer view of the adjustment for all models with actual data from that beach. 
The best model, after obtaining the potential with the function, is the one generated with the rational function. The rational function model produces very good adjustments, as Sierra et al. (1994 a, b) have demonstrated in their study of the Catalan coast. However, the rational function does not produce such small errors in volume as the potential function.

This research also aims to be a starting point for future studies, using new methods such as neural networks to adjust the equilibrium profile, including the influence of breakwaters as well as the mathematical modeling of an equilibrium profile that will be useful for minimizing volumetric errors.

\section{Conclusion}

For the analysis of the equilibrium profile on the Valencian coast, two types of profiles have been used: those obtained from Ecolevante (2006) bathymetry, in which a stretch of beach of about $62,519 \mathrm{~m}$ is dominant and precision profiles in which information from $17,680 \mathrm{~m}$ of coastline is available. Therefore it can be asserted that in $28.27 \%$ of the beaches studied, bathymetric profiles from 2006 and precision profiles from a time period (1992-2012) are available.

From conducted research emerges the variability of various parameters involved in obtaining the equilibrium profile. This is the case with the sediment median size $\mathrm{D}_{50}$, if we observe Table 1 and Fig. 4 we can conclude that the methodology in which least error occurs for the use of $\mathrm{D}_{50}$, is the one which obtains this parameter as if it were a single representative sample for the entire beach. This conclusion is emphasized by mistakes made in volume or surface and checking parameters such as MSE/Var, $\epsilon$ or prediction diagram, when the profile obtained from $\mathrm{D}_{50 \text {,arithmetic }}$ and $\mathrm{D}_{50 \text {,weight }}$ is checked using the Dean's formulations (1), (2) and (3) for Mediterranean beaches in Valencia.

Furthermore it has been found that the depth at which the equilibrium profile must be studied can be both $d_{i}$ and the $d_{1}$, as mistakes are similar with both depths. This makes sense as only sediments from storms move between $d_{i}$ and $d_{l}$, which only occurs for approximately 12 hours per year (Hallermeier, 1978, 1981b) and movements of more than $d_{1}$ are scarce compared to littoral zone.

From models obtained by analysis and testing through potential, rational, exponential and logarithmic functions, it can be observed that the potential function provides the best results. On the other hand, the relative mean squared error and the mean error are the parameters which most accurately describe the function which best fits the real data.

Therefore, from the research carried out it can be concluded that:

- Existing formulations are very sensitive to small changes in the calculation

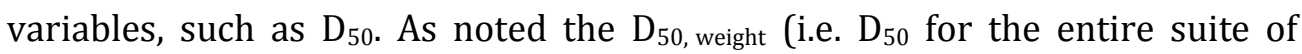

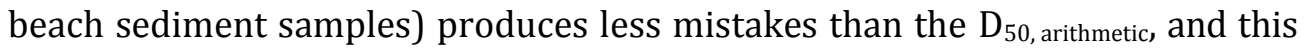
best represents the median particle size of the beach.

- The equilibrium profile can be obtained up to the depth $d_{i}$ or $d_{1}$, as the results are very similar. 
- Mistakes made by adjusting profiles from only one year are less than those made using functions validated in other study areas. Moreover these errors are acceptable in beach nourishment.

- This improved methodology can be used worldwide. E $\left(\mathrm{m}^{2}\right), \mathrm{MSE} / \mathrm{Var}, \epsilon$ and the prediction diagram are the parameters which best indicate the model adjustment.

- The model defined by the potential function is the one that best describes the profile shape in the study area, although the rational function also produces good results. 


\section{References}

Birkemeier, W.A., 1985. Field data on seaward limit of profile change. Journal of Waterway Port Coastal and Ocean Engineering-Asce. 111(3), 598-602.

Bodge, K.R., 1992. Representing equilibrium beach profiles with an exponential expression. Journal of Coastal Research. 8(1), 47-55.

Boon, J.D., Green, M.O., 1988. Caribbean beachface slopes and beach equilibrium profiles. Paper presented at the 21st Conference of Coastal Engineering.

Bruun, P., 1954. Coast Erosion and the Development of Beach Profiles. Vicksburg: Beach Erosion Board Technical Memorandum (Vol. 44): U.S. Army Engineer Waterway.

Capiobianco, M., Hanson, H., Larson, M., Steetzel, H., Stive, M.J.F., Chatelus, Y., Karambas, T., 2002. Nourishment design and evaluation: applicability of model concepts. Coastal Engineering, 47(2), 113-135.

Dai, Z.J., Du, J.Z., Li, C.C., Chen, Z.S., 2007. The configuration of equilibrium beach profile in South China. Geomorphology. 86(3-4), 441-454.

Davison, A.T., Nicholls, R.J., Leatherman, S.P., 1992. Beach nourishment as a coastal management tool: An annotated bibliography on developments associated with the artificial nourishment of beaches. Journal Coastal Research, 8, 984-1022.

Dean, R.G., 1977. Equilibrium Beach Profiles: U.S. Atlantic and Gulf Coasts. Department of Civil Engineering. Ocean Engineering Technical Report (Vol. 12. pp. 1-44). Newark. Delaware.: University of Delaware.

Dean, R.G., 1987. Coastal Sediment Processes: Toward Engineering Solutions. Paper presented at the Specialty Conference on Coastal Sediment 87.

Dean, R.G., 1991. Equilibrium beach profiles - characteristics and applications. Journal of Coastal Research. 7(1), 53-84.

Dean, R.G., 2003. Beach Nourishment Theory and Practice. Advanced Series on Ocean Engineering - Volume 18; World Scientific Publishing Co. pp. 34-37

Dean, R.G., Dalrymple. R.A., 2004. Coastal Processes with Engineering Applications: Cambridge University Press.

Dolan, R., Hayden. B.P., Felder, W., 1977. Systematic variations in inshore bathymetry. Journal of Geology. 85(2), 129-141.

Eagleson, P.S., Glenne, B., Dracup, J. A., 1963. Equilibrium Characteristics of Sand Beaches. Journal of the Hydraulics Division. 89(1), 35-57.

Ecolevante, (2006). Ecomapping study of the littoral from the provinces of Alicante and Valencia. State General Service of Coasts.

Folk, R.L., Ward, W.C., 1957. Brazos River bar: a study in the significance of grain size parameters. Journal of Sedimentary Research, 27(1).

Ghazali, M., Hisham, N., 2007. Determination of depths of closure along the Kelantan coast. Doctoral dissertation, Universiti Teknologi Malaysia, Faculty of Civil Engineering.

Grunnet, N.M., Walstra, D.J.R., Ruessink, B.G., 2004. Process-based modelling of a shoreface nourishment. Coastal Engineering, 51(7), 581-607.

Hallermeier, R.J., 1978. Uses for a calculated limit depth to beach erosion. 16th Coastal Engineering Conference;. American Society of Civil Engineers. Reston. VA. pp. 1493-1512. 
Hallermeier, R.J., 1981a. Fall velocity of beach sands. In C. E. R. Center (Ed.). Coastal Engineering Technical Note (Vol. CETN-II). Vicksburg, MS.: U.S. Army Engineer Waterways Experiment Station.

Hallermeier, R.J., 1981b. A profile zonation for seasonal sand beaches from wave climate. Coastal Engineering. 4(3), 253-277.

Hallermeier, R.J., 1983. Sand Transport Limits in Coastal Structure Design, Proceedings, Coastal Structures '83, American Society of Civil Engineers, pp. 703-716.

Hands, E.B., Allison, M.C., 1991. Mound migration in deeper water and methods of categorising active and stable depths. Proceedings of the ASCE Specialty Conference on Quantitative Approaches to Coastal Sediment Processes, Seattle, Washington, Vol. 2, 1985-1999.

Hayden, B.P., Felder. W., Fidher, J., Resio, D., Vincent, L., Dolan, R., 1975. Systematic variations in inshore bathymetry. Technical Report No. 10. Charlottesville. Virginia.: University of Virginia. Department of Enviromental Sciences.

Hinton, C., Nicholls, R.J., 1998. Spatial and temporal behaviour of depth of closure along the Holland coast. Proceedings of 26th International Conference on Coastal Engineering, ASCE, 2913-2925.

Houston, J.R., 1995. Beach Nourishment. Shore and Beach, 63 (1), 21-24.

Iglesias, G., López, I., Castro, A., Carballo, R., 2009a. Neural network modelling of planform geometry of headland-bay beaches. Geomorphology. 103, 577-587.

Iglesias, G., López, I., Castro, A., Carballo, R., 2009b. Headland-bay beach planform and tidal range. Geomorphology.112, 135-143.

Inman, D.L., Elwany, M.H.S., Jenkins, S.A., 1993. Shorerise and bar-berm profiles on ocean beaches. Journal of Geophysical Research: Oceans (1978-2012), 98(C10), 1818118199.

Jiménez, J.A., Sánchez-Arcilla, A., 1993. Medium-term coastal response at the Ebro delta, Spain. Marine Geology, 114(1), 105-118.

Kaiser, M.F.M., Frihy, O.E., 2009. Validity of the equilibrium beach profiles: Nile Delta Coastal Zone. Egypt. Geomorphology. 107(1), 25-31.

Karunarathna, H., Reeve, D.E., Spivack, M., 2009. Beach profile evolution as an inverse problem. Continental Shelf Research. 29(18), 2234-2239.

Komar, P.D., McDougal, W. G., 1994. The analysis of exponential beach profiles. Journal of Coastal Research. 10(1), 59-69.

Kraus, N. C., \& Harikai, S. (1983). Numerical model of the shoreline change at Oarai Beach. Coastal Engineering, 7(1), 1-28.

Kriebel. D.L., Kraus. N.C., Larson. M., 1991. Engineering methods for predicting beach profile response. Paper presented at the Coastal Sediments.

Larson, M., Kraus, N.C., 1992. Dynamics of longshore bars. Coastal Engineering Proceedings, 1 (23).

Moore, B., 1982. Beach profile evolution in response to changes in water level and water height. (MSc Thesis). University of Delaware.

Nicholls, R.J., Birkemeier, W.A., Lee. G.H., 1998. Evaluation of depth of closure using data from Duck. NC. USA. Marine Geology. 148(3-4), 179-201.

Noble, R.N., 1978. Coastal structures effects on shorelines. Proceedings of the 16th Coastal Engineering Conference, Hamburg, 2069-2485. 
Pilkey, O.H., Young, R.S., Riggs, S.R., Smith, A.W.S., Wu, H.Y., Pilkey. W.D., 1993. The concept of shoreface profile of equilibrium - a critical-review. Journal of Coastal Research. $9(1), 255-278$.

Rector, R.L., 1954. Laboratory study of equilibrium profiles of beaches. Beach Erosion Board. Vikcburg.: U.S. Army Engineer Waterway.

Rijkswaterstaat (Dutch Public Works Department), 1987. Manual on Artificial Beach Nourishment. Delft Hydraulics Laboratory. The Netherlands.

Romanczyk, W., Boczar-Karakiewicz, B., Bona, J.L., 2005. Extended equilibrium beach profiles. Coastal Engineering. 52(9), 727-744.

Saville, T., 1957. Scale effects in two dimensional beach studies. Paper presented at the 7th General Meeting of the Intenational Association of Hydraulic Research.

Serra, J., Medina. J.R., 1996. Beach monitoring program of Valencia (Spain). Paper presented at the 25th Coastal Engineering. Orlando. Florida.

Shinohara, K., Tsubaki, T., 1966. Model study on the change of shoreline of beach by the offshore breakwater. Proceedings of the 10th Coastal Engineering Conference ASCE, Tokyo, 550-563.

Sierra, J.P., Lo Presti, A., Sánchez-Arcilla Conejo, A., 1994a. An attempt to model longshore sediment transport on the catalan coast. Coastal Engineering. 190, 2625-2638.

Sierra, J.P., Lo Presti. A., Sánchez-Arcilla Conejo. A., 1994b. Representación del perfil de equilibrio en las playas del litoral catalán. Revista de Obras Públicas. 141, 33-46.

Stive, M.J., De Vriend, H.J., Nicholls, R.J., Capobianco, M., 1992. Shore nourishment and the active zone: A time scale dependent view. Proceedings of the Twenty-third Coastal Engineering Conference ASCE, New York, 2464-2473.

Stockberger, M.T., Wood, W.L., 1990. Application of Equilibrium Beach Concepts to Sandy Great Lake Profiles. Paper presented at the 22 Coastal Engineering Conference

Türker, U., Kabdaşl, M.S., 2006. The effects of sediment characteristics and wave height on shape-parameter for representing equilibrium beach profiles. Ocean Engineering. 33(2), 281-291.

Vellinga, P., 1984. A tentative description of a universal erosion profile for sandy beaches and rock beaches - reply. Coastal Engineering. 8(2), 177-188.

Waters, C.H., 1939. Equilibrium slopes of sea beaches. (MSc Thesis). University of California. Berkeley.

Wentworth, C.K., 1922. A Scale of grade and class terms for clastic sediments. The Journal of Geology. 30(5), 377-392. 


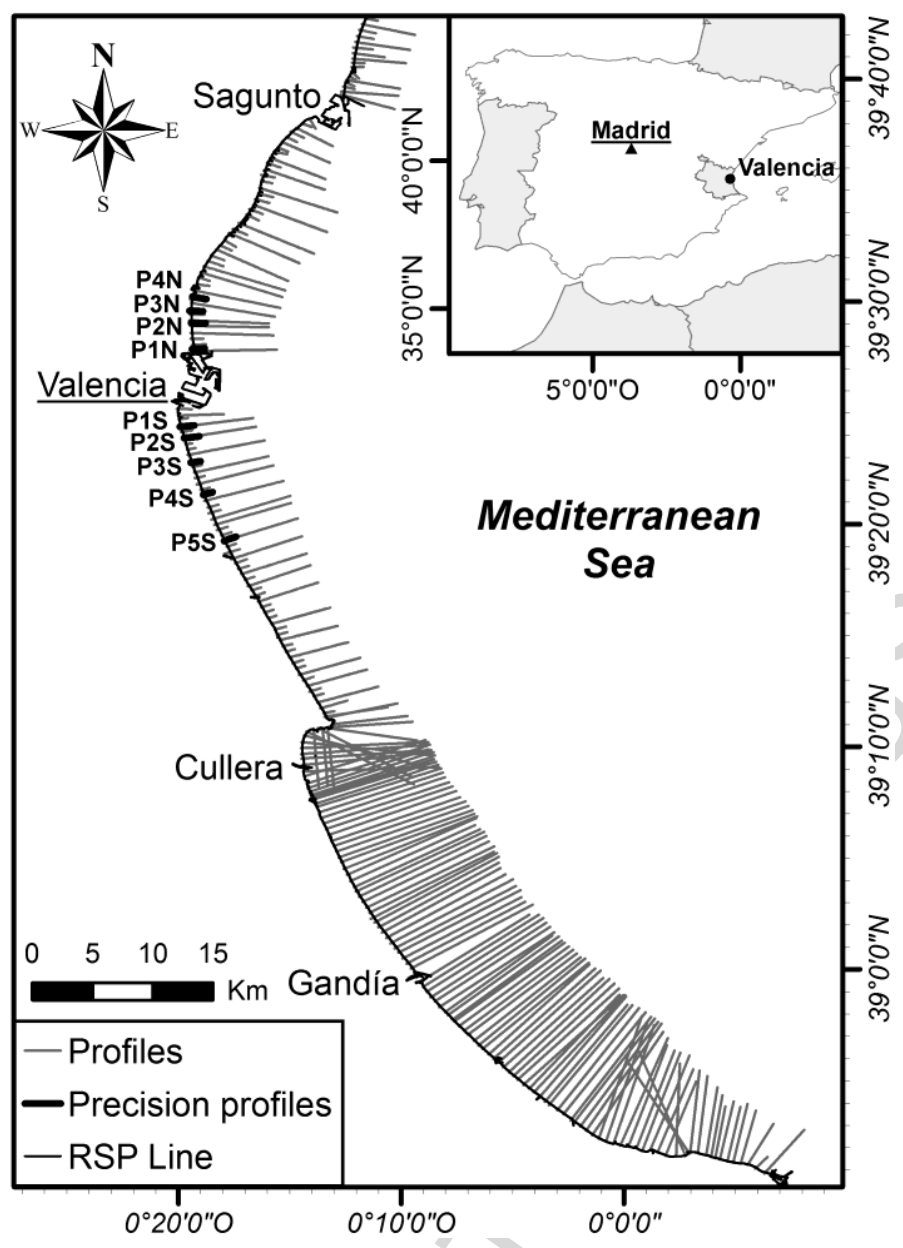

Fig. 1 

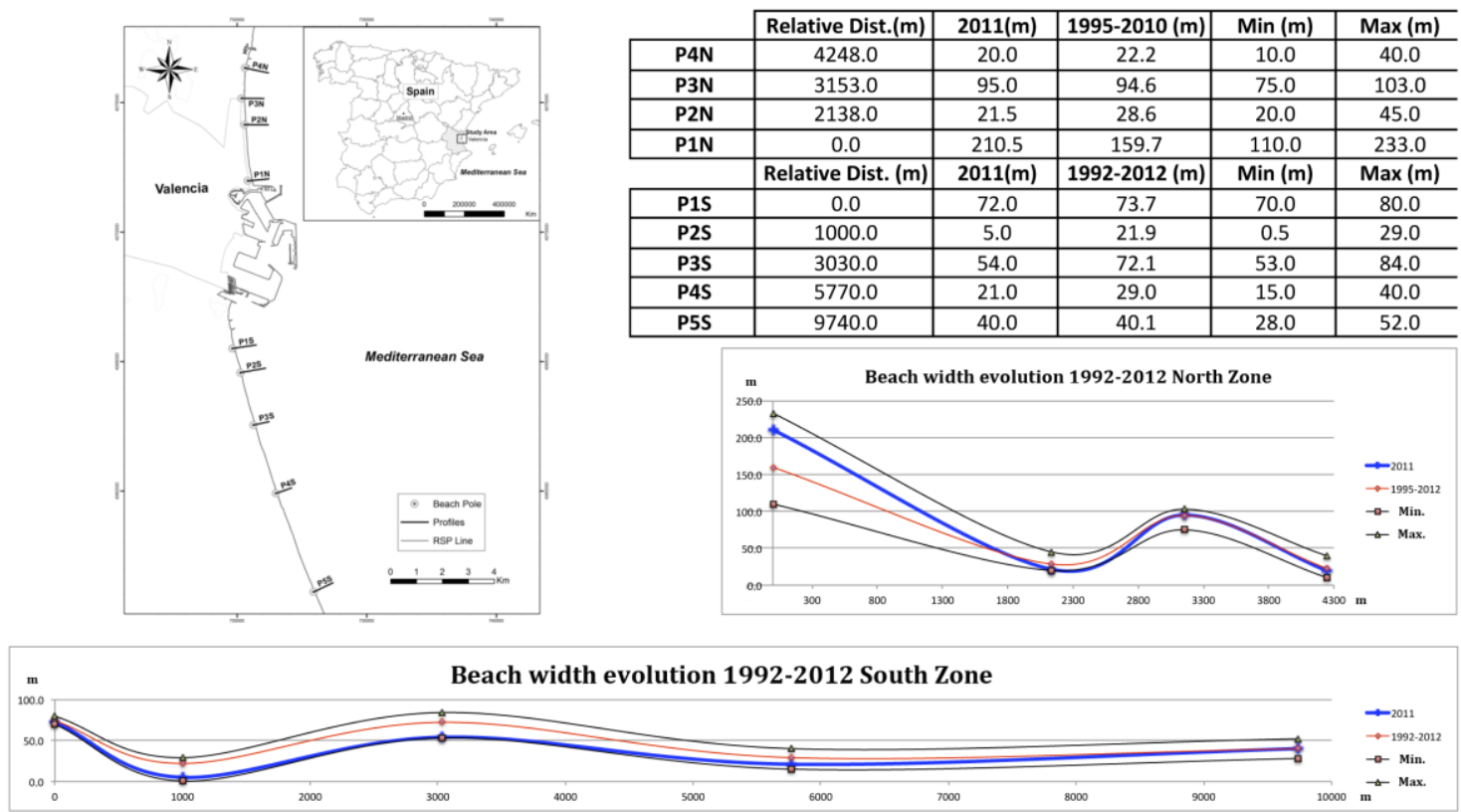

Fig. 2 


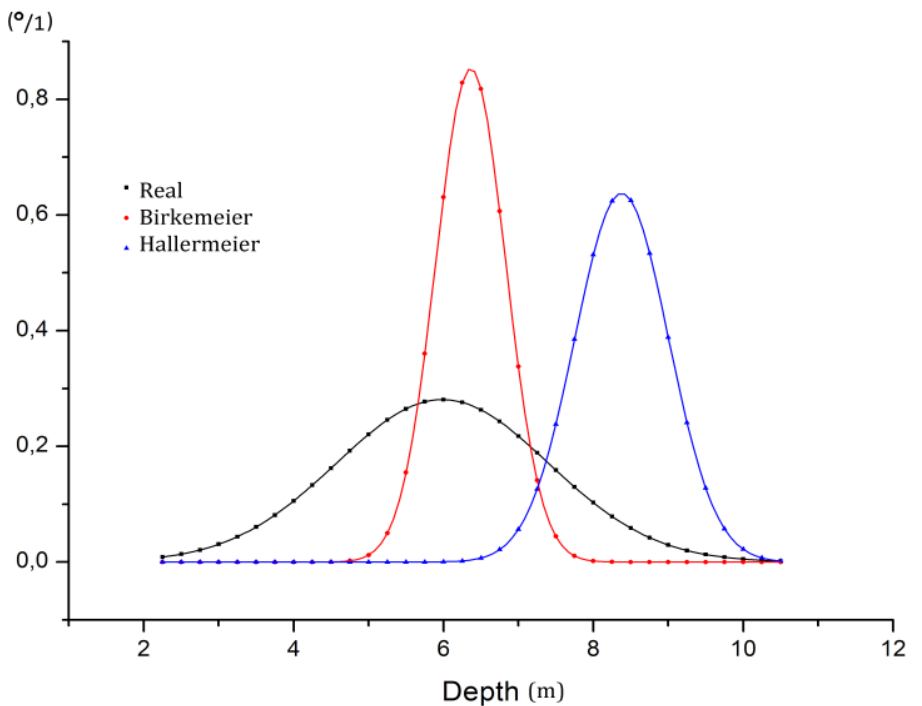

Fig. 3 


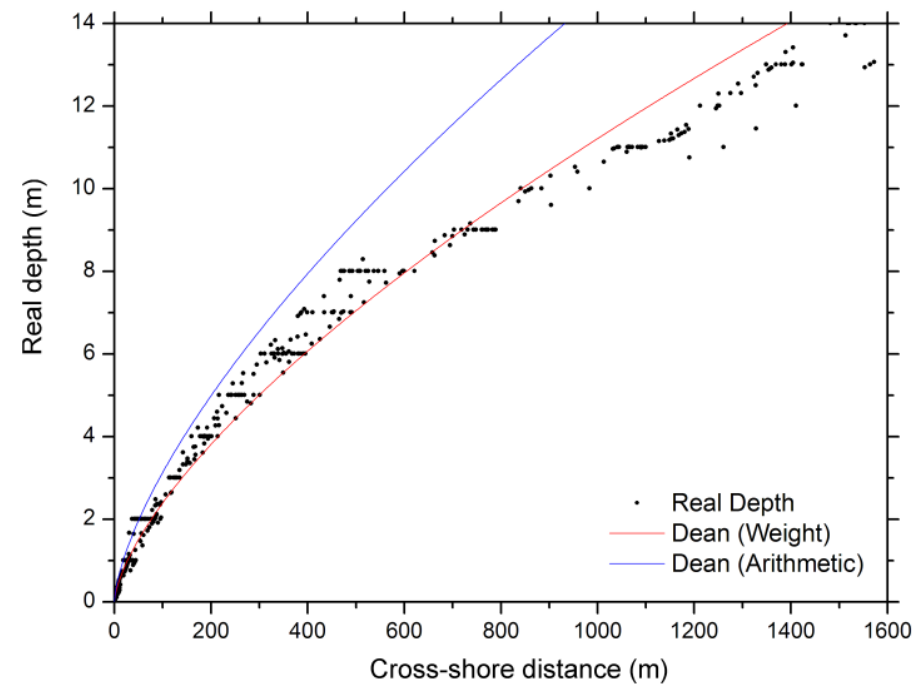

Fig. 4 

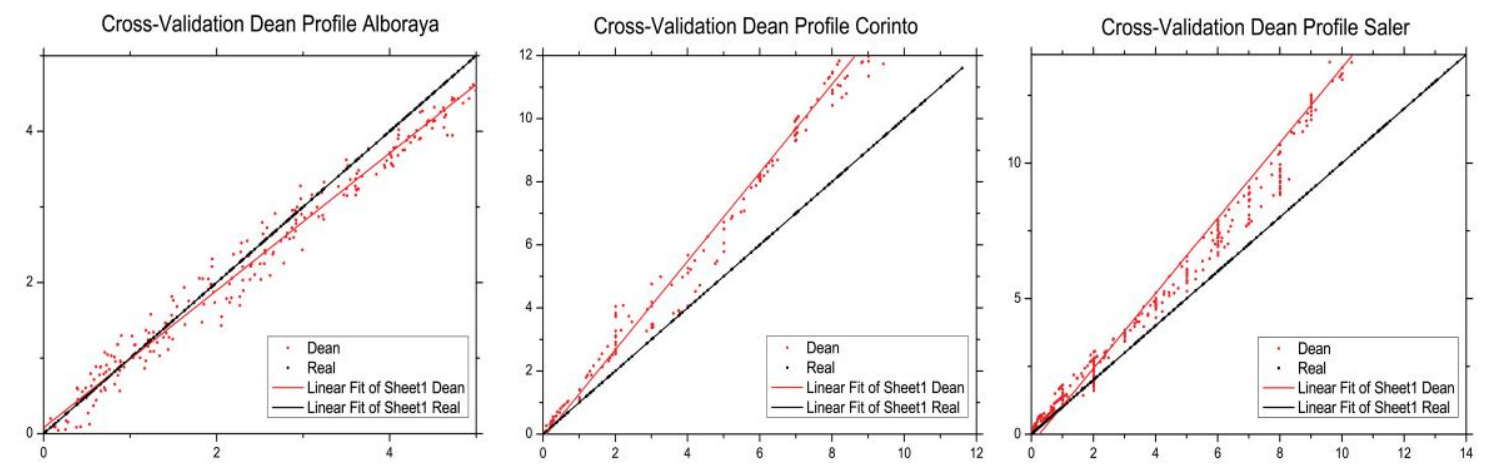

Fig. 5 

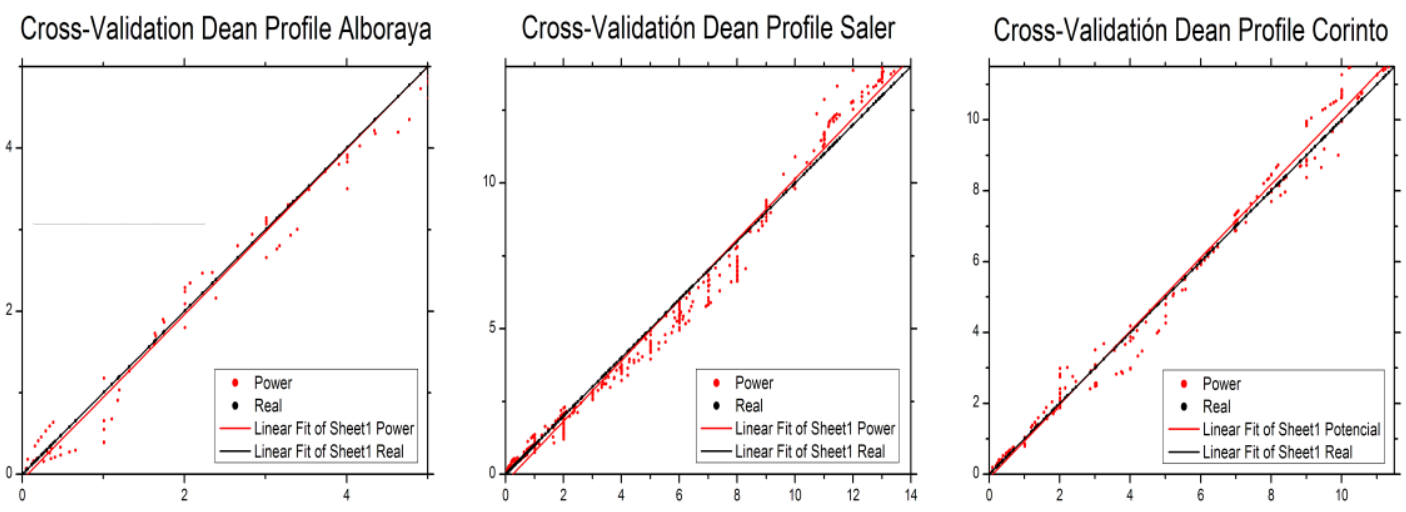

Fig. 6 


\section{Cross-Validation}

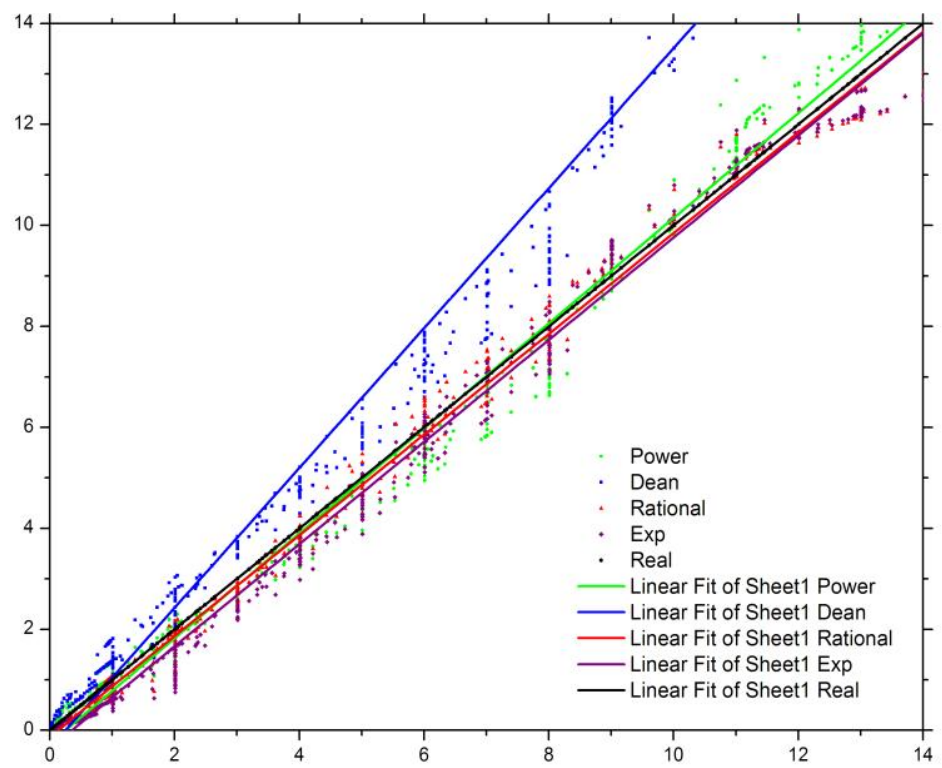

Fig. 7 
Beach Profile Comparation of Saler

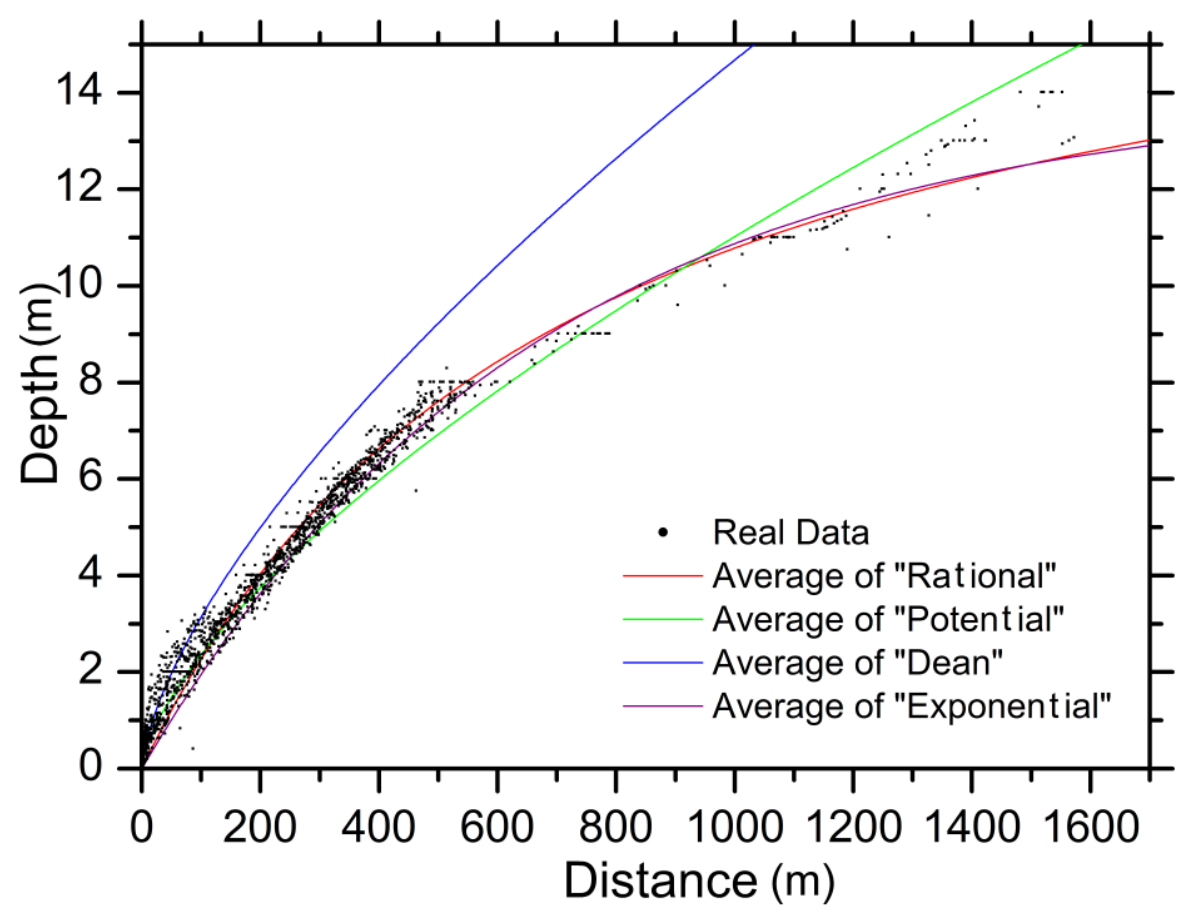

Fig. 8 
Table 1

\begin{tabular}{|l|r|r|}
\hline \multicolumn{3}{|c|}{ Volume error $\left(\mathbf{~}^{\mathbf{3}}\right.$ ) } \\
\hline Name of the Beach & Dean Weight & Dean Arithmetic \\
\hline Alboraya & 321,881 & 220,674 \\
\hline Cabañal-Malvarrosa & 694,882 & 591,995 \\
\hline Pinedo & 20,149 & 907,042 \\
\hline Saler & 589,247 & $10,871,080$ \\
\hline Dehesa & $2,082,168$ & $2,257,231$ \\
\hline Total & $\mathbf{3 , 7 0 8 , 3 2 7}$ & $\mathbf{1 4 , 8 4 8 , 0 2 3}$ \\
\hline
\end{tabular}


Table 2

\begin{tabular}{|c|c|c|c|c|c|c|c|c|}
\hline \multirow{2}{*}{ Name of the Beach } & \multicolumn{4}{|c|}{ DEAN D50,weight } & \multicolumn{4}{|c|}{ DEAN D50,aritmetic } \\
\hline & $\begin{array}{c}\text { D50,weigth } \\
\text { (mm) }\end{array}$ & $\mathbf{A}$ & $E\left(m^{2}\right)$ & $\mathbf{R}^{2}$ & $\begin{array}{c}\text { D50,artimetic } \\
\text { (mm) }\end{array}$ & A & $E\left(m^{2}\right)$ & $\mathbf{R}^{2}$ \\
\hline Almardá & 0.240 & 0.1059 & -425.9 & 0.982 & 0.332 & 0.1236 & -1399.617 & 0.9823 \\
\hline Canet de Berenguer & 0.208 & 0.0988 & 165.8 & 0.983 & 0.205 & 0.0981 & 191.019 & 0.983 \\
\hline Alboraya & 0.174 & 0.0907 & 153.0 & 0.988 & 0.179 & 0.0919 & 104.917 & 0.989 \\
\hline Cabañal-Malvarrosa & 0.167 & 0.0902 & 295.3 & 0.944 & 0.172 & 0.0902 & 251.540 & 0.944 \\
\hline Pinedo & 0.253 & 0.1086 & -6.4 & 0.962 & 0.281 & 0.1142 & -288.588 & 0.962 \\
\hline Saler & 0.258 & 0.1096 & -112.7 & 0.985 & 0.452 & 0.1434 & -310.557 & 0.986 \\
\hline Dehesa & 0.305 & 0.1188 & -429.4 & 0.991 & 0.311 & 0.1198 & -465.497 & 0.990 \\
\hline Recatí & 0.225 & 0.1026 & -39.0 & 0.997 & 0.226 & 0.1028 & -50.162 & 0.997 \\
\hline Perelló & 0.262 & 0.1104 & -279.7 & 0.992 & 0.261 & 0.1102 & -270.470 & 0.992 \\
\hline Mil Palmeras & 0.236 & 0.1050 & -74.5 & 0.983 & 0.234 & 0.1045 & -57.640 & 0.983 \\
\hline Rey & 0.256 & 0.1092 & -3224.82 & 0.986 & 0.256 & 0.1092 & -3212.79 & 0.986 \\
\hline Mareny & 0.258 & 0.1096 & -291.6 & 0.998 & 0.269 & 0.1118 & -390.438 & 0.998 \\
\hline San Lorenzo & 0.248 & 0.1075 & 146.0 & 0.995 & 0.250 & 0.1079 & 146.000 & 0.995 \\
\hline Dosel & 0.226 & 0.1028 & 4459.841 & 0.994 & 0.228 & 0.1032 & 4478.742 & 0.994 \\
\hline Tabernes de Valladigna & 0.325 & 0.1224 & -3121.8 & 0.991 & 0.334 & 0.1240 & -3312.138 & 0.990 \\
\hline Jaraco & 0.264 & 0.1108 & -802.2 & 0.996 & 0.258 & 0.1096 & -713.147 & 0.995 \\
\hline L'Ahuir & 0.233 & 0.1044 & -292.6 & 0.996 & 0.233 & 0.1044 & -292.6 & 0.996 \\
\hline Grao de Gandía & 0.211 & 0.0995 & 91.4 & 0.990 & 0.214 & 0.1002 & 59.999 & 0.989 \\
\hline Venecia & 0.231 & 0.1039 & -97.6 & 0.993 & 0.231 & 0.1039 & -97.6 & 0.993 \\
\hline Daimuz & 0.230 & 0.1037 & 1305.783 & 0.993 & 0.228 & 0.1033 & 1300.32 & 0.993 \\
\hline Bellreguard & 0.215 & 0.1004 & 1276.058 & 0.995 & 0.210 & 0.0993 & 1261.727 & 0.995 \\
\hline Miramar & 0.237 & 0.1052 & 101.2 & 0.996 & 0.238 & 0.1054 & 90.019 & 0.996 \\
\hline Piles & 0.239 & 0.1056 & 322.0 & 0.997 & 0.237 & 0.1052 & 357.948 & 0.997 \\
\hline Oliva-Terranova & 0.231 & 0.1039 & 272.0 & 0.999 & 0.231 & 0.1039 & 272.0 & 0.999 \\
\hline
\end{tabular}




\begin{tabular}{|l|c|c|c|c|c|c|c|c|}
\hline Oliva-Pau Pi & 0.220 & 0.1015 & 402.9 & 0.996 & 0.216 & 0.1006 & 464.611 & 0.996 \\
\hline Oliva L'Aigua Blanca & 0.207 & 0.0986 & 840.3 & 0.999 & 0.194 & 0.0956 & 1105.882 & 0.999 \\
\hline Oliva Rabdels & 0.308 & 0.1193 & -828.6 & 0.997 & 0.222 & 0.1019 & 486.15 & 0.997 \\
\hline Oliva-Les Deveses & 0.219 & 0.1013 & 142.4 & 0.995 & 0.240 & 0.1058 & -99.773 & 0.995 \\
\hline
\end{tabular}


Table 3

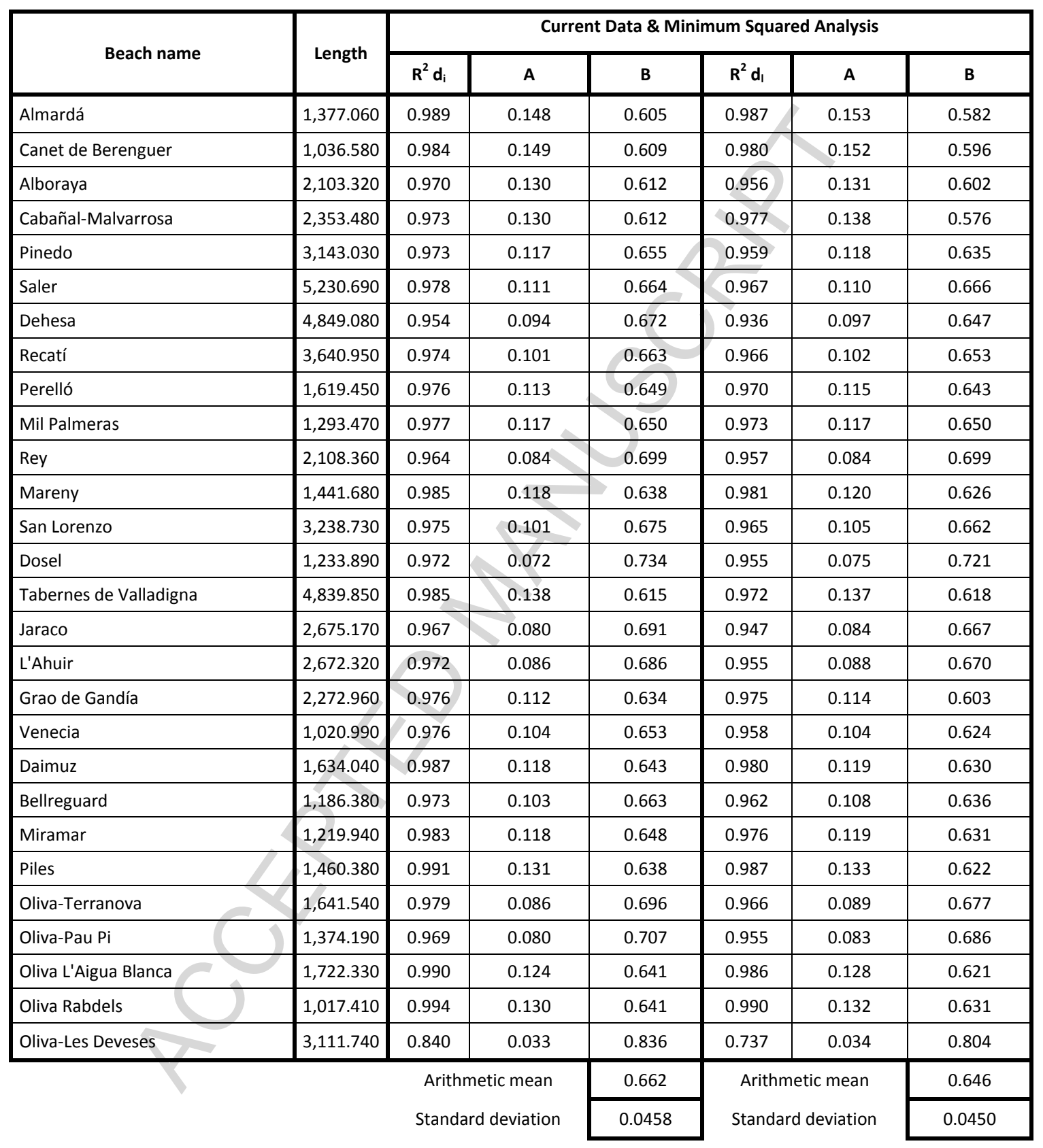


Table 4

\begin{tabular}{|c|c|c|c|c|c|c|c|c|c|c|c|c|}
\hline \multirow{2}{*}{$\begin{array}{l}\text { Name of The } \\
\text { Beach }\end{array}$} & \multicolumn{6}{|c|}{ POWER Function di } & \multicolumn{6}{|c|}{ POWER Function dl } \\
\hline & A & $E\left(m^{2}\right)$ & $R^{2}$ & MSE/Var & $\varepsilon$ & $\delta$ & A & $E\left(m^{2}\right)$ & $R^{2}$ & MSE/Var & $\varepsilon$ & $\delta$ \\
\hline Almardá & 0.0980 & 2.875 & 0.9830 & $2.36 \%$ & 0.5461 & 0.0910 & 0.9080 & 0.927 & 0.971 & $4.07 \%$ & 0.318 & 0.0728 \\
\hline $\begin{array}{l}\text { Canet de } \\
\text { Berenguer }\end{array}$ & 0.1033 & 1.909 & 0.9830 & $1.81 \%$ & 0.382 & 0.073 & 0.1007 & -1.102 & 0.964 & $4.53 \%$ & 0.3823 & 0.0728 \\
\hline Alboraya & 0.0947 & -1.318 & 0.9880 & $1.19 \%$ & 0.289 & 0.065 & 0.0968 & 0.088 & 0.983 & $1.81 \%$ & 0.382 & 0.073 \\
\hline $\begin{array}{l}\text { Cabañal- } \\
\text { Malvarrosa }\end{array}$ & 0.0975 & 0.424 & 0.9880 & $6.23 \%$ & 0.764 & 0.158 & 0.0865 & -0.095 & 0.955 & $5.38 \%$ & 0.361 & 0.147 \\
\hline Pinedo & 0.1084 & 2.231 & 0.9890 & $4.18 \%$ & 0.642 & 0.123 & 0.1258 & -0.110 & 0.974 & $3.90 \%$ & 0.307 & 0.135 \\
\hline Saler & 0.1077 & -2.516 & 0.9840 & $1.77 \%$ & 0.563 & 0.084 & 0.1198 & 0.523 & 0.986 & $1.51 \%$ & 0.276 & 0.080 \\
\hline Dehesa & 0.1055 & 0.215 & 0.9890 & $1.07 \%$ & 0.301 & 0.065 & 0.1027 & 0.080 & 0.961 & $4.28 \%$ & 0.323 & 0.133 \\
\hline Recatí & 0.1019 & -1.642 & 0.9900 & $0.31 \%$ & 0.198 & 0.033 & 0.1006 & -1.715 & 0.993 & $0.72 \%$ & 0.183 & 0.052 \\
\hline Perelló & 0.1043 & -1.008 & 0.9920 & $0.78 \%$ & 0.274 & 0.053 & 0.1050 & -0.273 & 0.986 & $1.53 \%$ & 0.257 & 0.072 \\
\hline Mil Palmeras & 0.1027 & 2.463 & 0.9920 & $1.90 \%$ & 0.434 & 0.080 & 0.1023 & 1.246 & 0.954 & $5.46 \%$ & 0.469 & 0.122 \\
\hline Rey & 0.1035 & -3.076 & 0.9940 & $0.65 \%$ & 0.332 & 0.053 & 0.1030 & -1.033 & 0.986 & $1.37 \%$ & 0.300 & 0.073 \\
\hline Mareny & 0.1030 & 2.200 & 0.9980 & $0.21 \%$ & 0.153 & 0.029 & 0.1023 & -1.442 & 0.994 & $0.61 \%$ & 0.141 & 0.048 \\
\hline San Lorenzo & 0.1088 & -3.913 & 0.9940 & $0.67 \%$ & 0.467 & 0.053 & 0.1035 & -0.608 & 0.996 & $0.43 \%$ & 0.141 & 0.048 \\
\hline Dosel & 0.1146 & -0.966 & 0.9890 & $1.33 \%$ & 0.819 & 0.066 & 0.1050 & -0.194 & 0.994 & $0.71 \%$ & 0.187 & 0.040 \\
\hline $\begin{array}{l}\text { Tabernes de } \\
\text { Valladigna }\end{array}$ & 0.0960 & -6.943 & 0.9880 & $1.50 \%$ & 0.485 & 0.061 & 0.1036 & 0.055 & 0.981 & $2.31 \%$ & 0.211 & 0.090 \\
\hline Jaraco & 0.0999 & -2.874 & 0.9950 & $0.48 \%$ & 0.254 & 0.045 & 0.1012 & -0.265 & 0.986 & $1.85 \%$ & 0.001 & 0.000 \\
\hline L'Ahuir & 0.1003 & -0.852 & 0.9960 & $0.38 \%$ & 0.227 & 0.038 & 0.0995 & -0.927 & 0.983 & $1.81 \%$ & 0.240 & 0.088 \\
\hline Grao de Gandía & 0.1015 & -0.879 & 0.9850 & $1.76 \%$ & 0.443 & 0.081 & 0.0942 & 0.272 & 0.991 & $1.45 \%$ & 0.221 & 0.078 \\
\hline Venecia & 0.1008 & -0.876 & 0.9930 & $0.68 \%$ & 0.217 & 0.052 & 0.0915 & -0.233 & 0.981 & $3.40 \%$ & 0.233 & 0.138 \\
\hline Daimuz & 0.1008 & -2.709 & 0.9850 & $1.51 \%$ & 0.431 & 0.060 & 0.1062 & 0.595 & 0.993 & $0.85 \%$ & 0.181 & 0.057 \\
\hline Bellreguard & 0.1066 & -2.081 & 0.9860 & $0.40 \%$ & 0.240 & 0.038 & 0.1042 & -0.879 & 0.995 & $1.07 \%$ & 0.200 & 0.066 \\
\hline Miramar & 0.1083 & -1.244 & 0.9960 & $0.53 \%$ & 0.234 & 0.038 & 0.1038 & -0.659 & 0.988 & $1.22 \%$ & 0.191 & 0.062 \\
\hline Piles & 0.1094 & 4.140 & 0.9970 & $0.31 \%$ & 0.227 & 0.031 & 0.1088 & -0.009 & 0.993 & $0.70 \%$ & 0.190 & 0.052 \\
\hline Oliva-Terranova & 0.1072 & 2.058 & 0.9980 & $0.24 \%$ & 0.209 & 0.029 & 0.1037 & 0.632 & 0.996 & $0.57 \%$ & 0.163 & 0.049 \\
\hline Oliva-Pau Pi & 0.1073 & 3.119 & 0.9930 & $0.65 \%$ & 0.295 & 0.049 & 0.1016 & -0.071 & 0.989 & $1.37 \%$ & 0.223 & 0.070 \\
\hline $\begin{array}{l}\text { Oliva L'Aigua } \\
\text { Blanca }\end{array}$ & 0.1082 & -3.025 & 0.9990 & $0.10 \%$ & 0.133 & 0.019 & 0.1059 & -1.378 & 0.997 & $0.35 \%$ & 0.121 & 0.035 \\
\hline Oliva Rabdels & 0.1084 & -1.059 & 0.9970 & $0.28 \%$ & 0.207 & 0.030 & 0.1103 & 0.957 & 0.992 & $0.82 \%$ & 0.171 & 0.057 \\
\hline $\begin{array}{l}\text { Oliva-Les } \\
\text { Deveses }\end{array}$ & 0.1084 & -1.059 & 0.9940 & $1.21 \%$ & 0.375 & 0.071 & 0.1052 & -0.346 & 0.967 & $4.15 \%$ & 0.342 & 0.142 \\
\hline
\end{tabular}


Table 5

\begin{tabular}{|l|c|c|c|c|c|c|c|c|c|}
\hline Beach name & $\begin{array}{c}\text { Shoreline length } \\
(\mathbf{m})\end{array}$ & $\mathbf{A}(\mathbf{d i})$ & $\mathbf{\%}$ & $\mathbf{A}(\mathbf{d l})$ & $\%$ & $\begin{array}{c}\text { Surface error } \\
\mathbf{d}_{\mathbf{i}}\left(\mathbf{m}^{2} / \mathbf{u d}\right) \\
(\mathbf{1 9 9 5 - 1 9 9 7 )}\end{array}$ & $\begin{array}{c}\text { Surface error } \\
\mathbf{d}_{\mathbf{i}}\left(\mathbf{m}^{2} / \mathbf{u d}\right) \\
(\mathbf{2 0 0 8 - 2 0 1 2})\end{array}$ & $\begin{array}{c}\text { Surface error } \\
\mathbf{d}_{\mathbf{l}}\left(\mathbf{m}^{2} / \mathbf{u d}\right) \\
(\mathbf{1 9 9 5 - 1 9 9 7 )}\end{array}$ & $\begin{array}{c}\text { Surface error } \\
\mathbf{d}_{\mathbf{l}}\left(\mathbf{m}^{2} / \mathbf{u d}\right) \\
(\mathbf{2 0 0 8 - 2 0 1 2})\end{array}$ \\
\hline Alboraya & $2,103.320$ & 0.003 & $2.72 \%$ & 0.000 & $0.21 \%$ & -38.071 & 32.617 & -8.985 & 13.655 \\
\hline $\begin{array}{l}\text { El Cabañal- } \\
\text { Malvarrosa }\end{array}$ & $2,353.480$ & -0.005 & $-5.06 \%$ & 0.002 & $1.70 \%$ & 65.857 & -79.933 & 16.857 & -27.956 \\
\hline Pinedo & $3,143.030$ & 0.001 & $1.00 \%$ & -0.016 & $-14.26 \%$ & NO DATA & NO DATA & NO DATA & NO DATA \\
\hline Saler & $5,230.690$ & 0.007 & $6.43 \%$ & -0.005 & $-4.54 \%$ & -12.991 & 13.626 & -19.676 & 36.019 \\
\hline Dehesa & $4,849.080$ & 0.009 & $7.62 \%$ & 0.017 & $14.42 \%$ & -72.215 & -14.353 & -39.573 & 18.611 \\
\hline
\end{tabular}


Table 6

\begin{tabular}{|c|c|c|c|c|c|c|c|c|c|c|c|c|c|c|}
\hline \multirow{2}{*}{ Name of The Beach } & \multicolumn{7}{|c|}{ RATIONAL } & \multicolumn{7}{|c|}{ EXPONENTIAL } \\
\hline & A & B & $E\left(m^{2}\right)$ & $\mathbf{R}^{2}$ & MSE/Var & $\varepsilon$ & $\delta$ & $\mathbf{A}_{\mathrm{T}}$ & $\mathbf{B}_{\mathrm{T}}$ & $E\left(m^{2}\right)$ & $R^{2}$ & MSE/Var & $\varepsilon$ & $\delta$ \\
\hline Almardá & 62.634 & 0.0300 & -42.356 & 0.9800 & $2.01 \%$ & 0.507 & 0.0839 & 99.7440 & 0.0100 & -418.326 & 0.9900 & $1.00 \%$ & 0.358 & 0.0596 \\
\hline Canet de Berenguer & 47.366 & 0.0500 & -21.988 & 0.9690 & $3.07 \%$ & 0.499 & 0.0951 & 23.3860 & 0.0430 & -66.854 & 0.9820 & $1.78 \%$ & 0.380 & 0.0723 \\
\hline Alboraya & 44.723 & 0.0720 & 12.295 & 0.9850 & $1.49 \%$ & 0.325 & 0.0731 & 6.2170 & 0.1640 & 232.285 & 0.9690 & $3.07 \%$ & 0.467 & 0.1049 \\
\hline Cabañal-Malvarrosa & 45.067 & 0.0510 & -328.747 & 0.9610 & $7.50 \%$ & 0.841 & 0.1739 & 6.2170 & 0.1640 & 327.332 & 0.9690 & $7.02 \%$ & 0.813 & 0.1682 \\
\hline Pinedo & 28.149 & 0.0810 & -54.4541 & 0.9910 & $0.91 \%$ & 0.301 & 0.0575 & 6.2170 & 0.1640 & 920.541 & 0.9690 & $14.91 \%$ & 1.215 & 0.2321 \\
\hline Saler & 38.735 & 0.0540 & 100.231 & 0.9910 & $0.93 \%$ & 0.408 & 0.0605 & 4.7870 & 0.2240 & 600.833 & 0.9540 & $4.55 \%$ & 0.904 & 0.1340 \\
\hline Dehesa & 44.865 & 0.0510 & -54.435 & 0.9880 & $1.25 \%$ & 0.324 & 0.0705 & 7.4760 & 0.1390 & 229.753 & 0.9780 & $2.22 \%$ & 0.433 & 0.0942 \\
\hline Recatí & 28.149 & 0.0810 & -248.397 & 0.9345 & $7.46 \%$ & 0.975 & 0.1638 & 13.0000 & -0.0015 & 77.787 & 0.9825 & $1.82 \%$ & 0.482 & 0.0809 \\
\hline Perelló & 47.091 & 0.0480 & -12.659 & 0.9800 & $2.00 \%$ & 0.442 & 0.0860 & 15.0000 & -0.0013 & -89.485 & 0.9819 & $2.55 \%$ & 0.498 & 0.0971 \\
\hline Mil Palmeras & 45.067 & 0.0510 & -759.503 & 0.9610 & $3.83 \%$ & 0.618 & 0.1144 & 15.0000 & -0.0013 & -138.010 & 0.9654 & $4.78 \%$ & 0.691 & 0.1278 \\
\hline Rey & 53.237 & 0.0380 & 21.636 & 0.9820 & $1.76 \%$ & 0.550 & 0.0881 & 17.0000 & -0.0011 & -140.419 & 0.9808 & $2.36 \%$ & 0.636 & 0.1019 \\
\hline Mareny & 50.323 & 0.0450 & 14.450 & 0.9890 & $1.06 \%$ & 0.344 & 0.0647 & 13.0000 & -0.0017 & -296.429 & 0.9831 & $2.52 \%$ & 0.530 & 0.0998 \\
\hline San Lorenzo & 64.274 & 0.0230 & 131.708 & 0.9920 & $0.78 \%$ & 0.501 & 0.0564 & 24.0000 & -0.0007 & -377.042 & 0.9907 & $1.23 \%$ & 0.631 & 0.0711 \\
\hline Dosel & 60.894 & 0.0210 & -214.514 & 0.9930 & $0.75 \%$ & 0.617 & 0.0501 & 24.0000 & -0.0007 & 371.298 & 0.9902 & $1.53 \%$ & 0.877 & 0.0712 \\
\hline Tabernes de Valladigna & 50.009 & 0.0520 & 99.306 & 0.9850 & $1.46 \%$ & 0.479 & 0.0605 & 12.0000 & -0.0019 & -483.084 & 0.9723 & $3.09 \%$ & 0.696 & 0.0879 \\
\hline Jaraco & 48.351 & 0.0520 & -5.468 & 0.9940 & $0.60 \%$ & 0.285 & 0.0503 & 11.5000 & -0.0019 & -147.865 & 0.9898 & $1.03 \%$ & 0.375 & 0.0662 \\
\hline L'Ahuir & 50.504 & 0.0480 & -21.488 & 0.9920 & $0.78 \%$ & 0.325 & 0.0547 & 11.5000 & -0.0018 & 68.126 & 0.9873 & $1.38 \%$ & 0.434 & 0.0730 \\
\hline Grao de Gandía & 57.429 & 0.0340 & -9.325 & 0.9910 & $0.91 \%$ & 0.320 & 0.0586 & 12.5000 & -0.0017 & -260.471 & 0.9834 & $1.95 \%$ & 0.469 & 0.0860 \\
\hline Venecia & 39.071 & 0.0770 & 12.967 & 0.9960 & $0.41 \%$ & 0.171 & 0.0409 & 11.5000 & -0.0018 & -60.725 & 0.9937 & $1.30 \%$ & 0.303 & 0.0725 \\
\hline Daimuz & 42.720 & 0.0580 & 90.529 & 0.9920 & $0.77 \%$ & 0.308 & 0.0429 & 12.5000 & -0.0018 & -331.883 & 0.9908 & $2.04 \%$ & 0.019 & 0.0027 \\
\hline Bellreguard & 46.499 & 0.0470 & 16.075 & 0.9970 & $0.28 \%$ & 0.204 & 0.0325 & 12.6000 & -0.0018 & -120.069 & 0.9929 & $0.73 \%$ & 0.327 & 0.0522 \\
\hline Miramar & 45.193 & 0.0530 & 83.580 & 0.9950 & $0.63 \%$ & 0.258 & 0.0422 & 12.7000 & -0.0018 & -262.192 & 0.9937 & $1.47 \%$ & 0.394 & 0.0643 \\
\hline Piles & 47.934 & 0.0410 & -30.283 & 0.9930 & $0.67 \%$ & 0.338 & 0.0454 & 12.7000 & -0.0019 & -125.149 & 0.9808 & $1.90 \%$ & 0.570 & 0.0767 \\
\hline Oliva-Terranova & 52.379 & 0.0370 & -33.117 & 0.9960 & $0.40 \%$ & 0.272 & 0.0378 & 12.7000 & -0.0019 & -0.646 & 0.9803 & $2.07 \%$ & 0.617 & 0.0858 \\
\hline Oliva-Pau Pi & 53.541 & 0.0360 & 33.165 & 0.9950 & $0.53 \%$ & 0.268 & 0.0441 & 12.9000 & -0.0018 & -310.378 & 0.9810 & $2.44 \%$ & 0.573 & 0.0943 \\
\hline Oliva L'Aigua Blanca & 50.913 & 0.0390 & 50.727 & 0.9950 & $0.50 \%$ & 0.340 & 0.0477 & 12.5000 & -0.0020 & -236.194 & 0.9740 & $2.73 \%$ & 0.794 & 0.1116 \\
\hline Oliva Rabdels & 45.342 & 0.0470 & 20.959 & 0.9920 & $0.77 \%$ & 0.342 & 0.0494 & 12.0000 & -0.0021 & -223.954 & 0.9828 & $1.80 \%$ & 0.525 & 0.0757 \\
\hline Oliva-Les Deveses & 45.501 & 0.0540 & 22.841 & 0.9930 & $0.71 \%$ & 0.287 & 0.0529 & 10.5000 & -0.0023 & -100.505 & 0.9879 & $1.26 \%$ & 0.384 & 0.0707 \\
\hline
\end{tabular}


Table 7

\begin{tabular}{|c|c|c|c|c|c|c|}
\hline \multicolumn{7}{|c|}{ Relative volumes } \\
\hline BEACH NAME & Dean Weight & Arithmetic & Dean & Rational & Exponential & Potential \\
\hline Alboraya & 0.659 & & 0.452 & 0.053 & 1.000 & 0.006 \\
\hline Cabañal-Malvarrosa & 0.898 & & 0.765 & 1.000 & 0.996 & 0.001 \\
\hline Pinedo & 0.007 & & 0.313 & 0.059 & 1.000 & 0.002 \\
\hline Saler & 0.054 & & 1.000 & 0.048 & 0.289 & 0.001 \\
\hline Dehesa & 0.922 & & 1.000 & 0.117 & 0.494 & 0.000 \\
\hline$\%$ Relative total & $67.2 \%$ & & $93.4 \%$ & $33.8 \%$ & $100.0 \%$ & $0.3 \%$ \\
\hline \multicolumn{7}{|c|}{$\mathbf{R}^{2}$} \\
\hline BEACH NAME & Dean Weight & Arithmetic & Dean & Rational & Exponential & Potential \\
\hline Alboraya & 0.988 & & 0.989 & 0.985 & 0.969 & 0.988 \\
\hline El Cabañal-Malvarrosa & 0.944 & & 0.944 & 0.961 & 0.969 & 0.988 \\
\hline Pinedo & 0.962 & & 0.962 & 0.991 & 0.969 & 0.989 \\
\hline Saler & 0.985 & & 0.985 & 0.991 & 0.954 & 0.984 \\
\hline Dehesa & 0.991 & & 0.991 & 0.988 & 0.978 & 0.989 \\
\hline Average & 0.974 & & 0.974 & 0.983 & 0.968 & 0.988 \\
\hline \multicolumn{7}{|c|}{ MSE/Var } \\
\hline BEACH NAME & Dean Weight & Arithmetic & Dean & Rational & Exponential & Potential \\
\hline Alboraya & $1.57 \%$ & $+\infty$ & $1.34 \%$ & $1.49 \%$ & $3.07 \%$ & $1.19 \%$ \\
\hline Cabañal-Malvarrosa & $9.46 \%$ & $\nabla$ & $8.76 \%$ & $7.50 \%$ & $7.02 \%$ & $6.23 \%$ \\
\hline Pinedo & $4.18 \%$ & & $4.91 \%$ & $0.91 \%$ & $14.91 \%$ & $4.18 \%$ \\
\hline Saler & $2.00 \%$ & & $33.26 \%$ & $0.93 \%$ & $4.55 \%$ & $1.77 \%$ \\
\hline Dehesa & $4.94 \%$ & & $5.63 \%$ & $1.25 \%$ & $2.22 \%$ & $1.07 \%$ \\
\hline Average & $4.43 \%$ & & $10.78 \%$ & $2.42 \%$ & $6.35 \%$ & $2.89 \%$ \\
\hline \multicolumn{7}{|c|}{$\varepsilon$} \\
\hline BEACH NAME & Dean Weight & Arithmetic & Dean & Rational & Exponential & Potential \\
\hline Alboraya & 0.332 & & 0.307 & 0.325 & 0.467 & 0.289 \\
\hline Cabañal-Malvarrosa & 0.941 & & 0.906 & 0.841 & 0.813 & 0.764 \\
\hline Pinedo & 0.642 & & 0.696 & 0.301 & 1.215 & 0.642 \\
\hline Saler & 0.563 & & 2.442 & 0.408 & 0.904 & 0.563 \\
\hline Dehesa & 0.646 & & 0.689 & 0.324 & 0.433 & 0.301 \\
\hline Average & 0.625 & & 1.008 & 0.440 & 0.767 & 0.512 \\
\hline \multicolumn{7}{|c|}{$\delta$} \\
\hline Beach name & Dean Weight & Arithmetic & Dean & Rational & Exponential & Potential \\
\hline Alboraya & 0.075 & & 0.069 & 0.073 & 0.105 & 0.065 \\
\hline Cabañal-Malvarrosa & 0.195 & & 0.187 & 0.174 & 0.168 & 0.158 \\
\hline Pinedo & 0.123 & & 0.133 & 0.057 & 0.232 & 0.123 \\
\hline Saler & 0.084 & & 0.363 & 0.061 & 0.134 & 0.084 \\
\hline Dehesa & 0.140 & & 0.150 & 0.071 & 0.094 & 0.065 \\
\hline Average & 0.123 & & 0.181 & 0.087 & 0.147 & 0.099 \\
\hline
\end{tabular}




\section{Highlights}

- Development of a method to obtain an equilibrium beach profile model.

- Model validation using one-year beach profile database.

- The results for EBP are similar when its limit is DoC or offshore offshore.

- $\mathrm{D}_{50 \text {, weight }}$ sampling and calculation method is the best input for profile models.

- Formula provides best adjustments for the beach profiles on the Valencian shore. 